\title{
Numerical-experimental observation of shape bistability of red blood cells flowing in a microchannel
}

\author{
Achim Guckenberger, ${ }^{1}$ Alexander Kihm, ${ }^{2}$ Thomas John, ${ }^{2}$ Christian Wagner, ${ }^{2,3}$ and Stephan Gekle ${ }^{1}$ \\ ${ }^{1}$ Biofluid Simulation and Modeling, Fachbereich Physik, Universität Bayreuth, Bayreuth \\ ${ }^{2}$ Experimental Physics, Saarland University, 66123, Saarbrücken, Germany \\ ${ }^{3}$ Physics and Materials Science Research Unit, University of Luxembourg, Luxembourg, Luxembourg
}

(Dated: November 19, 2017)

\begin{abstract}
Red blood cells flowing through capillaries assume a wide variety of different shapes owing to their high deformability. Predicting the realized shapes is a complex field as they are determined by the intricate interplay between the flow conditions and the membrane mechanics. In this work we construct the shape phase diagram of a single red blood cell with a physiological viscosity ratio flowing in a microchannel. We use both experimental in-vitro measurements as well as 3D numerical simulations to complement the respective other one. Numerically, we have easy control over the initial starting configuration and natural access to the full $3 \mathrm{D}$ shape. With this information we obtain the phase diagram as a function of initial position, starting shape and cell velocity. Experimentally, we measure the occurrence frequency of the different shapes as a function of the cell velocity to construct the experimental diagram which is in good agreement with the numerical observations. Two different major shapes are found, namely croissants and slippers. Notably, both shapes show coexistence at low $(<1 \mathrm{~mm} / \mathrm{s})$ and high velocities $(>3 \mathrm{~mm} / \mathrm{s})$ while in-between only croissants are stable. This pronounced bistability indicates that RBC shapes are not only determined by system parameters such as flow velocity or channel size, but also strongly depend on the initial conditions.
\end{abstract}

\section{INTRODUCTION}

Red blood cells (RBCs) are the major constituent of mammalian blood and therefore determine the majority of its flow properties. One of the most amazing features of RBCs is their deformability, allowing them to squeeze through channels with diameters much smaller than their own equilibrium size [1-3]. Another consequence of their deformability is the wide range of stationary and nonstationary shapes assumed by the RBCs in microchannel flows with dimensions similar to or slightly larger than the $\mathrm{RBC}$ equilibrium radius [4-6]. Understanding and being able to predict these shapes is of high importance for a variety of reasons. From a fundamental point of view, it serves as the foundation in a bottom-up approach to understand the properties of red blood cell suspensions which are chiefly determined by single particle behavior [7-12]. From an applied perspective, a series of recent investigations have devised promising approaches for sorting cells based on their mechanical properties either in lateral displacement devices [13] or using high-speed video microscopy [14]. Finally, knowledge of the precise cell shape is also essential for accurately measuring geometric properties of cells [15].

The most frequently observed shapes of RBCs in microchannel flows are the so-called "croissant" and "slipper" shapes. Examples are depicted in figure 1. Some researchers refer to croissants also as parachutes, although here we prefer the term croissant since our shapes are not perfectly rotationally symmetric (similar to the ones found by Farutin and Misbah [16]). Probably one of the earliest experimental study on isolated red blood cells in flow was performed by Gaehtgens et al. [17], where slippers as well as parachutes have been found depending on the diameter of the cylindrical channel. Suzuki et al. [18] presented a phase diagram of parachutes and slippers as a function of velocity and confinement in a cylindrical tube. Slippers dominated at smaller diameters and higher velocities. Secomb et al. [19] compared experiments with 2D simulations in cylindrical channels of $8 \mu \mathrm{m}$ diameter for a cell velocity of approximately $1.25 \mathrm{~mm} / \mathrm{s}$. Furthermore, two other publications [20, 21] considered the flow of RBCs at very low viscosity ratios of $\lambda \lesssim 0.27$. They presented a phase diagram showing parachutes and slippers, where the velocity was varied in the very high regime of 10 to $170 \mathrm{~mm} / \mathrm{s}$. Tomaiuolo et al. [22] found parachutes at smaller and slippers at higher velocities in cylindrical channels of $10 \mu \mathrm{m}$ diameter. A subsequent study [23] as well as Prado et al. [24] considered the transient during start-up of the flow. Cluitmans et al. [25] detected croissants at lower $(\lesssim 5 \mathrm{~mm} / \mathrm{s})$ and slippers at higher velocities $(\gtrsim 10 \mathrm{~mm} / \mathrm{s})$ in rectangular channels with widths $\leqslant 10 \mu \mathrm{m}$. Moreover, Quint et al. [26] found a stable slipper and a metastable croissant at the same set of parameters in a wider channel of $25 \mu \mathrm{m} \times 10 \mu \mathrm{m}$. Other publications presenting experiments in channel flow also touch the subject of RBC shapes but focus on other aspects such as the methodology [27-34], dense suspensions and cell interactions [17, 21,34-41] or use vastly larger channel diameters [12, 42].

Numerical simulations and semi-analytical calculations of isolated particles in microchannels mostly studied axisymmetric $\mathrm{RBCs}$ [43-45] or $2 \mathrm{D}$ vesicles [5, 6, 46-51]. The numerical work by Aouane et al. [5], for example, identified a large amount of dynamics including deterministic chaos. The first full 3D simulation of single cells with a realistic $\mathrm{RBC}$ model (but with a ratio of inner to outer viscosity of $\lambda=1$ ) was conducted by Noguchi and Gompper [52] who used a cylindrical tube with a diameter of $9.2 \mu \mathrm{m}$. They found the typical discocyte shape below 

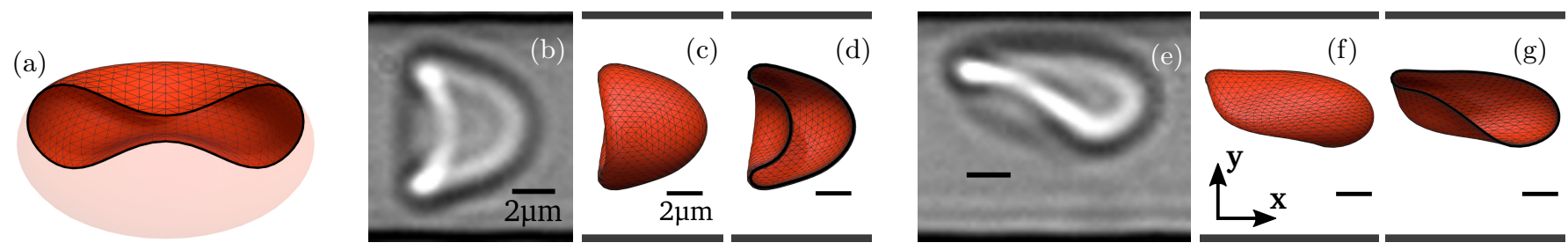

Figure 1. Typical RBC shapes from simulations and experiments. (a) The typical discocyte shape employed in some of the simulations as the starting shape. Half of it was made transparent for illustration purposes. Its horizontal diameter is $8 \mu \mathrm{m}$. (b) A typical croissant observed in the experiments when applying a pressure drop of $100 \mathrm{mbar}$ (cell velocity $(0.98 \pm 0.07) \mathrm{mm} / \mathrm{s}$ ). (c) A croissant with a velocity of $\approx 1.1 \mathrm{~mm} / \mathrm{s}$ obtained from the numerical simulations. (d) The cross-section of the croissant from (c). (e) A slipper from the experiments at $500 \mathrm{mbar}$ (cell velocity $(5.16 \pm 0.11) \mathrm{mm} / \mathrm{s}$ ). (f) A typical slipper from the simulations with a cell velocity of $\approx 5.2 \mathrm{~mm} / \mathrm{s}$. (g) The cross-section of the slipper from (f). The black lines on the shapes from the simulations depict the mesh. The bottom and top black lines in all figures are the walls $\left(L_{y} \approx 12 \mu \mathrm{m}\right.$ apart $)$, while the small black lines are scale bars of length $2 \mu \mathrm{m}$. The flow is in the positive $x$-direction (except in figure (a) where no flow exists).

and parachutes above a critical velocity which depends on the elastic parameters. A subsequent study by the same group additionally explored this threshold as a function of confinement [53]. Moreover, Fedosov et al. [4] presented very detailed phase-diagrams where the velocity and confinement was varied for three different sets of elastic moduli and a viscosity ratio of $\lambda=1$. They observed four distinct regions where snaking, tumbling, slippers and parachutes occurred. Recently, Ye et al. [54] considered the shapes of an $\mathrm{RBC}$ with $\lambda=1$ in rectangular microchannels (with width $10 \mu \mathrm{m}$ and aspect ratios 1 to 2 ) for the three cell velocities 4,20 and $100 \mathrm{~mm} / \mathrm{s}$ and observation times up to $\approx 0.03 \mathrm{~s}$. Snapshots after this short initial transient showed parachutes or slightly slipper-like shapes.

Bistability, i.e. the observation of two different stable shapes depending on the initial condition but at otherwise identical system parameters, was barely considered so far. It was observed only numerically for simpler situations such as close-to-spherical vesicles in unbounded Poiseuille flow [16] or near a single wall [55], for a 2D RBC model in bounded Poiseuille flow [19], for the initial transient of a red blood cell in a rectangular channel [54] or for simple shear flows $[12,56-58]$. No systematic experimental investigations exist for cells flowing in microchannels. Moreover, the 3D simulations and experimental investigations that were mentioned above and that consider the $\mathrm{RBC}$ shapes in microchannels in more detail all used a viscosity ratio of $\lambda \leqslant 1$, although $2 \mathrm{D}$ simulations showed that choosing a physiologically more realistic value of $\lambda \approx 5$ [59] can significantly affect RBC dynamics [6, 49].

Here we present a detailed systematic experimentalnumerical study on the steady-state shape of isolated red blood cells in a rectangular microchannel. We use the physiological viscosity ratio of $\lambda=5$ appropriate for healthy human red blood cells in the microcirculation [59]. The initial position is varied in the simulations directly, while experimentally we determine it via measurements at the channel entrance. Our central finding is that the initial starting position of the $\mathrm{RBC}$ has a decisive influence on the final steady-state shape of the red blood cell.
We begin by outlining our experimental and numerical methods in section II. Afterwards, the results from our experiments (section III) and simulations (section IV) are presented, while section $\mathrm{V}$ is dedicated to their detailed comparison. Finally, we conclude our work in section VI.

\section{METHODS}

\section{A. Experimental setup}

The sample preparation and experimental setup is mostly identical to the one used recently by Clavería et al. [35]. In short, human red blood cells were obtained from healthy donors by needle-prick and used within three hours. After appropriate preparation [35], they are suspended in a phosphate buffered saline (PBS) and bovine serum albumin solution which has a viscosity of approximately $1 \mathrm{mPas}$. The viscosity ratio of the cells is therefore $\lambda \approx 5[26]$. This value corresponds to the typical physiological value of healthy red blood cells in blood plasma [59]. The RBCs are pumped through rectangular, PDMS-based channels by a high-precision pressure device (Elveflow OB 1, MK II) with pressure drops ranging from 20 to 1000 mbar at room temperature. The channels have a cross-section width of $L_{y}=(11.9 \pm 0.3) \mu \mathrm{m}$ and a height of $L_{z}=(9.7 \pm 0.3) \mu \mathrm{m}$ without any applied pressure drop and are thus similar to the vessel diameters found in the microvascular system [60]. We use rectangular rather than cylindrical channels since they are easier to manufacture, are therefore prevalent in lab-on-a-chip devices and have the merit that cells are not rotated randomly around their axis due to the missing rotational symmetry. The latter property greatly simplifies the microscopic observation and analysis of the RBCs.

The hematocrit (volume percentage of RBCs) in the reservoir before the inlet is always $\lesssim 1.0 \%$, i.e. very low. Nevertheless, we find cells flowing in clusters as well as single cells. For the present work we have analyzed only the latter. To this end, previous experimental and theoretical results showed that the hydrodynamic interaction 
in a linear channel decays exponentially, and becomes negligible if the inter-particle distance is more than twice the channel width [53,61,62]. Considering that our channel has the dimensions $\approx 12 \mu \mathrm{m} \times 10 \mu \mathrm{m}$, cells can be considered as being single for distances $\gtrsim 25 \mu \mathrm{m}$. We only used cells that were at least $40 \mu \mathrm{m}$ apart from other entities.

We perform measurements at two locations along the channel, namely at the entrance $(x=0 \mathrm{~mm})$ and at $x=10 \mathrm{~mm}$ downstream. Vessel lengths in-between bifurcations in the microvascular system are less than $1 \mathrm{~mm}$, i.e. much shorter [63]. Nevertheless, this is not necessarily true for in-vitro experiments or lab-on-a-chip devices, and the long-time behavior also holds information about the general intrinsic properties. The flowing RBCs are recorded by an inverted bright-field microscope (Nikon TE 2000-S) with an oil-immersion objective (Nikon CFI Plan Fluor $60 \times, \mathrm{NA}=1.25)$ and a high-resolution camera (Fastec HiSpec 2G) at a frame rate of 400 frames per second. The camera is aligned along the $z$-direction so that the photographs show the cells in the $x$ - $y$-plane (compare figure 2). Hence, determination of the $z$-position is not possible, but also not absolutely necessary as our simulations always show a $z$-position of nearly 0 (see section $\mathrm{V}$ ). We analyze the recorded image sequence with a custom MATLAB script that detects each projected cell shape and the corresponding $2 \mathrm{D}$ center of mass position. It additionally tracks the cell position over the image sequence to obtain the individual cell velocity. Considering the optical setup, we assume an uncertainty in the position measurements of $\pm s_{\mathrm{P}}$ with $s_{\mathrm{P}}=0.1 \mu \mathrm{m}$.

\section{B. Simulation setup}

The numerical simulations mimic our experimental setup as far as possible. Hence, we place a single red blood cell in a rectangular channel as shown in figure 2 . The channel has a cross-section of width $L_{y}=12 \mu \mathrm{m}$ and height $L_{z}=10 \mu \mathrm{m}$. Periodic boundary conditions are assumed in the $x$-direction with a periodicity of $L_{x}=42.7 \mu \mathrm{m}$, in agreement with above estimates for the decay of hydrodynamic interactions.

We vary the initial $y$ - $z$-position (relative to the channel center) of the RBC's centroid along the line $z_{\text {init }}=$ $5 y_{\text {init }} / 9$, which almost corresponds to the channel diagonal. The corresponding initial radial position is thus simply given by $r_{\text {init }}=\sqrt{y_{\text {init }}^{2}+z_{\text {init }}^{2}}$. When starting with the typical discocyte equilibrium shape [64, 65], as depicted in figure $1(\mathrm{a})$, the RBC axis is aligned with the channel axis (as shown in figure 2). Cell velocities are extracted by considering the difference of the centroids between successive time steps. During the simulation, we monitor several quantities such as the radial, $y$ - and $z$-positions, the RBC asphericity or the cell velocity as well as the full 3D shape to determine when a steady state has been reached.

Regarding the actual modeling of the constituents, the

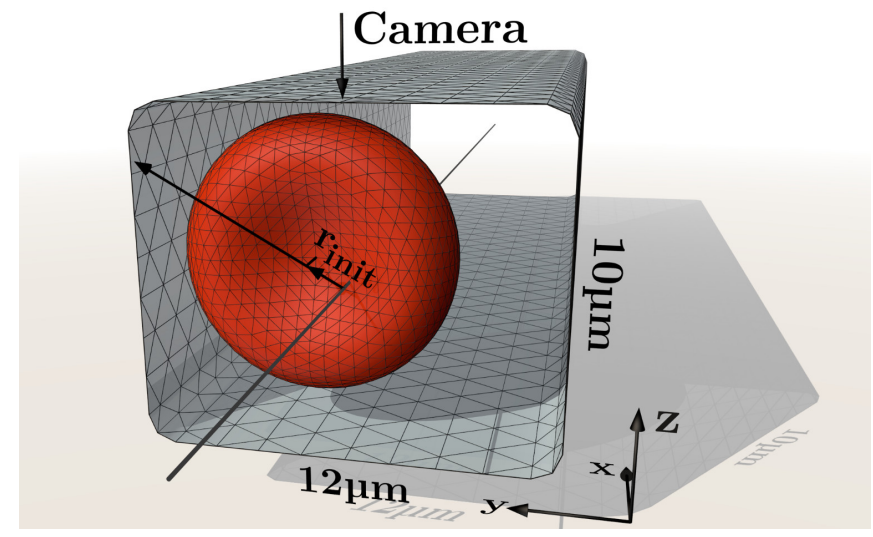

Figure 2. Simulation setup: A single red blood cell is placed in a rectangular channel of width $L_{y}=12 \mu \mathrm{m}$ and height $L_{z}=10 \mu \mathrm{m}$. Periodic boundary conditions are employed. Initially, the centroid of the cell is offset from the center axis along the left black arrow by a distance $r_{\text {init }}$. The depicted $\mathrm{RBC}$ illustrates the discocyte starting shape, although other shapes have been used, too. Furthermore, the black lines on the surfaces illustrate the employed meshes. The arrow at the top shows the view from the camera in the experiments (i.e. onto the $x$-y-plane) and the flow is in the positive $x$-direction.

RBC is filled with a Newtonian fluid with a dynamic viscosity $\mu_{\mathrm{RBC}}$, whereas the ambient flow is a Newtonian fluid with the dynamic viscosity $\mu=1.2 \times 10^{-3} \mathrm{~kg} /(\mathrm{s} \mathrm{m})$ of blood plasma [66-68]. We set the viscosity ratio $\lambda=$ $\mu_{\mathrm{RBC}} / \mu$ to a value of 5 in all simulations. The surface area of the RBC is set to $140 \mu^{2}$ and the volume is set to $100 \mathrm{\mu m}^{3}$ (see e.g. references 67 and 69), leading to a large radius of $R_{\mathrm{RBC}}=4 \mu \mathrm{m}$ when the cell is in the typical discocyte equilibrium shape (figure 1(a)). The mechanics of the infinitely thin membrane are governed by Skalak's law [70, 71] for the in-plane elasticity with a shear modulus of $\kappa_{\mathrm{S}}=5 \times 10^{-6} \mathrm{~N} / \mathrm{m}[72,73]$ and an area dilatation modulus of $\kappa_{\mathrm{A}}=100 \kappa_{\mathrm{S}}$. This value for $\kappa_{\mathrm{A}}$ ensures that the area changes remain below $2 \%$ in all cases. We take the reference state for the Skalak model to be the typical discocyte shape $[64,65]$. The membrane is additionally endowed with some bending resistance which is modeled according to the Canham-Helfrich law [74-76], where the bending modulus is fixed to $\kappa_{\mathrm{B}}=3 \times 10^{-19} \mathrm{~N} \mathrm{~m}$ $[73,77]$. The spontaneous curvature is set to zero.

We use 2048 flat triangles to discretize the RBC in our numerical implementation. The forces are computed as described by Guckenberger et al. [78], with Method C therein being used for the bending contribution. An unavoidable artificial volume drift of the cell is countered by adjusting the velocity to obey the no-flux condition and by a subsequent rescaling of the object [79, 80]. Moreover, the channel is represented by 2166 flat triangles. The corners are rounded to prevent numerical problems (compare figure 2). Rather than prescribing a zero velocity at the channel walls, we use a penalty method for efficiency reasons with a spring constant of $\kappa_{\mathrm{W}}=1.9 \times 10^{7} \mathrm{~N} / \mathrm{m}^{3}$ $[6,80]$. Increasing the triangle counts and the box length 
$L_{x}$ did not change the results significantly.

The Reynolds number in the considered system is defined as $\operatorname{Re}=2 R_{\mathrm{RBC}} u_{\max } \rho / \mu$. For a velocity of $u_{\text {max }} \leqslant 10 \mathrm{~mm} / \mathrm{s}$ and the density $\rho \approx 10^{3} \mathrm{~kg} / \mathrm{m}^{3}$ of the ambient and inner liquid we therefore have $\operatorname{Re}<0.1$. Hence, the flow can be appropriately described using the Stokes equation. This allows us to employ the boundary integral method (BIM) [81] for 3D periodic systems [80, 82]. Note that this method requires to prescribe a certain average flow through the whole unit cell instead of a pressure drop within the channel. The latter is unfortunately not easily accessible. We therefore compare with experiments by means of cell velocities. Continuing, the integrals are computed by a standard Gaussian quadrature with 7 points per triangle in conjunction with linear interpolation of nodal quantities and appropriate singularity removal for the single- and double-layer potentials [80]. Furthermore, we use the smooth particle mesh Ewald (SPME) method [83] to accelerate the computation of the periodic Green's functions; cutoff errors are kept below $5 \times 10^{-5}$. The resulting linear system is solved via GMRES [84] up to a residuum of $10^{-5}$, and the kinematic condition is integrated in time using the adaptive BogackiShampine algorithm [85] with the absolute tolerance set to $10^{-5} R_{\mathrm{RBC}}$. When the run-times are normalized to a two-socket system with 28 cores, each simulation took 1 to 29 days, with an average of around 5 days. The phase diagrams below are formed by 329 of such simulations in total. Further details on the numerical method as well as verifications of the implementation can be found in our previous publications $[26,78,80,86]$.

\section{EXPERIMENTAL RESULTS}

We classify cells in the experiments either as croissants, slippers or "other" not uniquely identifiable or completely different shapes. Typical slipper and croissant shapes are shown in the photographs (b) and (e) of figure 1. See the supplementary information (SI) for a collection of all images.

To systematically investigate the occurrence of the different shapes, we vary the imposed pressure drops from 20 to $1000 \mathrm{mbar}$. The corresponding cell velocities range from $0.14 \mathrm{~mm} / \mathrm{s}$ to $10.6 \mathrm{~mm} / \mathrm{s}$, covering the whole physiological range in microchannels [60, 87, 88]. We consider the cells $10 \mathrm{~mm}$ away from the channel entrance where most of the cells reached a steady state [35]. Figure 3(a) depicts the fraction of observed shapes as a function of the measured cell velocities, constituting our central result from the experiments. This distribution was obtained by considering typically more than 100 cells per imposed pressure drop. The average velocities were computed by averaging over all cells at a certain pressure drop, with the horizontal error bars showing the corresponding standard deviations $\sigma_{u}$ in cell velocity. Not all velocities are the same because croissants and slippers have different velocities at otherwise identical flow conditions [26], and because of the natural variations of cell properties such as elasticity and size, as also noted by Tomaiuolo et al. [22]. See the supplementary information for more details. Considering figure 3(a), high velocities obviously favor slippers while croissants are the most prominent for medium velocities. A pronounced peak exists from around 1 to $2 \mathrm{~mm} / \mathrm{s}$. Very small velocities produce mostly shapes that fall outside our simple two-state classification.

Figure 3(b) illustrates the corresponding estimated probability density function of the center of mass $y$ position of the cells at the various pressure drops. This estimate was obtained from the measured $y$-positions by using the kernel density estimator as implemented in MATLAB R2017a (ksdensity) with a support of $[-6,6] \mu \mathrm{m}$ and otherwise default settings. Thus, croissants and "others" occurring at lower velocities are centered in the channel, while slippers occurring at high velocities show a pronounced off-centered position. The assumed shapes therefore imply a certain $y$-position within the channel with slippers being off-centered and croissants centered. This is confirmed when analyzing the offset distribution separately for each shape class as shown in the supplementary information.

From figure 3(a) it is tempting to conclude that the flow velocity is the major parameter that determines the RBC shape with low velocities favoring centered and high velocities favoring off-centered flow positions. However, looking at the cell positions near the channel entrance (figure 4) we find that already upon entering the channel RBCs are not homogeneously distributed. At low velocities we observe a clear bias towards a centered initial position, with the distribution becoming approximately homogeneous only at the highest measured velocities. These experimental observations allow two distinct parameters as the reason for the dominance of the slipper shapes at high velocities: either the higher flow velocity itself or the more off-centered entry into the channel. To disentangle these two possibilities we now present numerical simulations whose geometry directly corresponds to the experimental setup.

\section{NUMERICAL RESULTS}

We numerically study the behavior of a single RBC in a rectangular microchannel by varying the imposed flow velocity, the initial shape and the initial offset $r_{\text {init }}$ from the centerline of the tube (see section II B). After starting the flow, we wait until the $\mathrm{RBC}$ reaches the steady state where the shape as well as the radial position does no longer change, or alternatively until periodic motion is observed.

In the majority of cases, we observe two different states: A croissant shape (which moves as a rigid body, figure 1(c)) and a slipper shape (figure 1(f)). The latter exhibits tank-treading (TT) and oscillatory contractions similar to the slippers seen by Fedosov et al. [4] (see the SI for a movie and the insets in figure 5). Tank-treading refers 

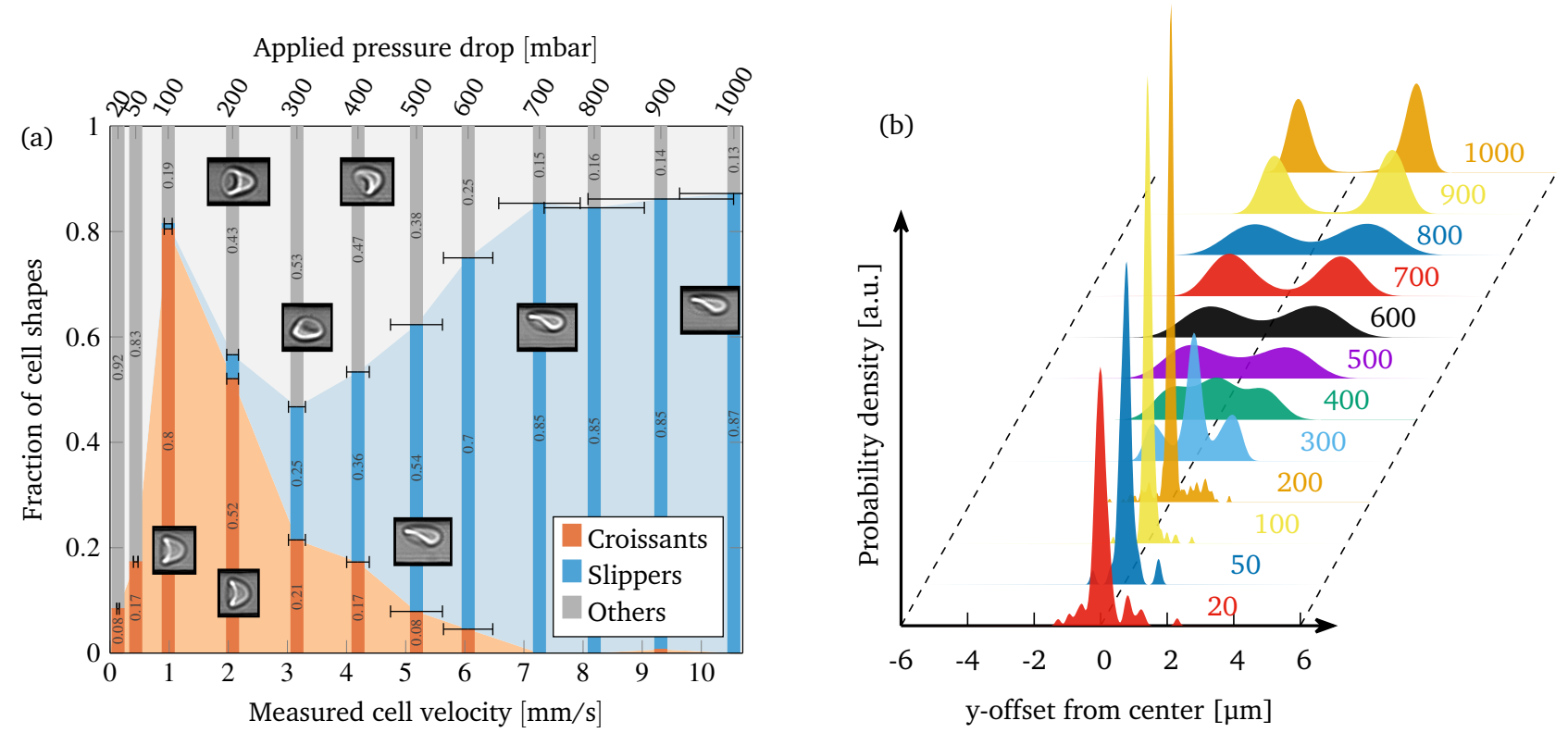

Figure 3. Experimental results: (a) Fraction of observed cell shapes as a function of the applied pressure drop (top axis) and mean cell velocity (bottom axis). The horizontal error bars depict the standard deviation of the measured cell velocities for each applied pressured drop. The shaded background is a guide to the eye. Furthermore, the insets show examples of experimental images (see the SI for a collection of all photographs). (b) Estimated probability density function of the RBCs' center-of-mass $y$-position within the channel for various pressure drops (indicated as numbers on the right in millibar) for all shapes combined. We show the separated contributions of each shape to the distribution in the supplementary information. The area under the curves is normalized to one. The dashed lines illustrate the wall positions. Both figures are for the position $10 \mathrm{~mm}$ downstream from the channel entrance.

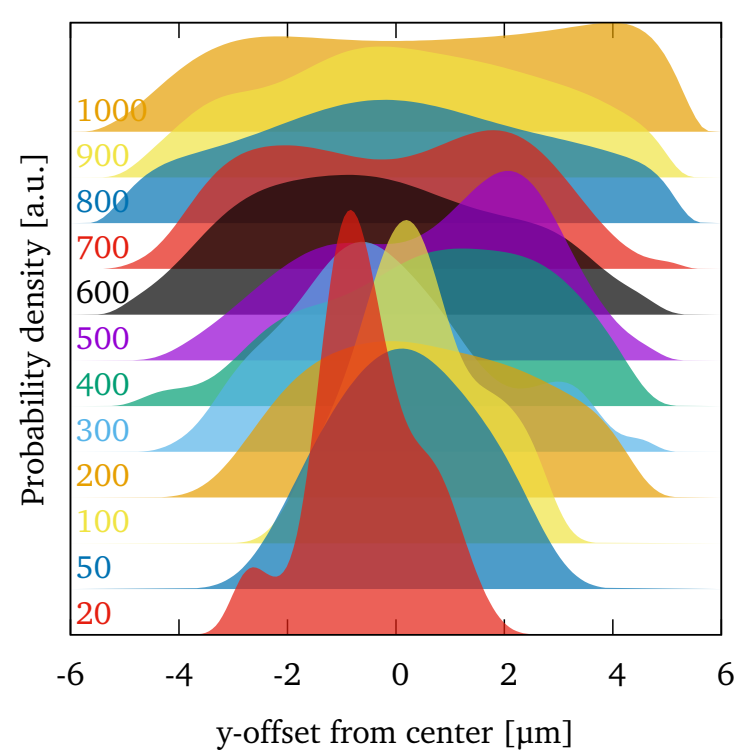

Figure 4. Experimental results: Estimated probability density function of the cells' center-of-mass $y$-position at the channel entrance (position $x=0 \mathrm{~mm}$ ). The pressure drops increase from the bottom (20 mbar) to the top (1000 mbar) with the numbers on the left side indicating the corresponding value in millibar. The area under the curves is normalized to one. The curves are offset in the vertical direction for illustration purpose. to the motion of the membrane around a (more or less) static shape. Note that perfectly axisymmetric parachutes are suppressed by the rectangular channel flow, contrary to the situation for cylindrical tubes [4] or unbounded Poiseuille flows [16].

To start the systematic study, we take a red blood cell that is initially in the typical discocyte shape with its rotation axis aligned along the tube's axis (cf. fig. 2). We then vary the radial offset $r_{\text {init }}$ from the center line as described in section II B and record the final radial position as well as the shape. The mean of the radial position is extracted by a temporal average once the cell is in the steady state (see the supplementary information for more details). Figure 5 shows the result for a cell velocity of $\approx 6.5 \mathrm{~mm} / \mathrm{s}$. A single sharp transition at $r_{\text {init }} \approx 0.7 \mu \mathrm{m}$ from centered croissants to off-centered slippers is observed. The final position of the slippers is mostly offset only along the wider width of the channel ( $y$-direction), but not along the smaller height ( $z$-direction). Hence we find pronounced bistability: The result is significantly determined by the initial condition and two different shapes coexist. This is consistent with the $2 \mathrm{D}$ simulations by Secomb et al. [19] and Tahiri et al. [6]. It also agrees qualitatively with observations by Farutin and Misbah for 3D simulations of vesicles in unbounded Poiseuille flow [16].

To study the bistability in more detail, we vary the imposed flow velocity as well as the initial offset $r_{\text {init }}$ 


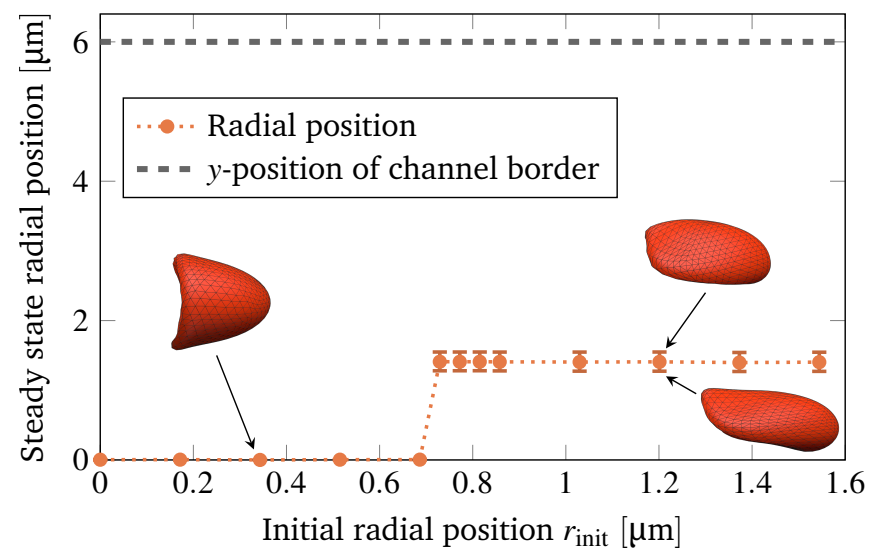

Figure 5. Simulation results: Averaged radial position in the steady state as a function of the initial radial offset for a cell velocity of $\approx 6.5 \mathrm{~mm} / \mathrm{s}$. The $\mathrm{RBC}$ starts in the typical discocyte shape with its rotation axis aligned with the tube's axis (figure 2). The dotted line is a guide to the eye. Half of the channel's extent along the $y$-direction (width) is shown as a dashed line at the top. The extent in the $z$-direction (height) is of less significance here since the steady states are always almost centered in the $z$-direction. Furthermore, the radial position for the converged slippers oscillates around a mean value and their shapes show periodic "contractions" as indicated by the vertical error bars and the right two insets, respectively.

and characterize the behavior in the steady state. This yields the shape phase diagram depicted in figure 6(a). The cell velocity is extracted in the steady state via a temporal average. For slippers the velocity varies periodically (similar to the radial position): the minimum and maximum in one period is indicated by the horizontal error bars. Overall, the mean cell velocity $u$ ranges from $0.132 \mathrm{~mm} / \mathrm{s}$ to $10.4 \mathrm{~mm} / \mathrm{s}$, matching with the experimentally covered range. The corresponding shear capillary number $\mathrm{Ca}_{\mathrm{S}}:=\mu u / \kappa_{\mathrm{S}}$ varies therefore in the interval $\mathrm{Ca}_{\mathrm{S}} \in[0.0317,2.50]$, while the bending capillary number $\mathrm{Ca}_{\mathrm{B}}:=\mu u R_{\mathrm{RBC}}^{2} / \kappa_{\mathrm{B}}$ lies in the range $\mathrm{Ca}_{\mathrm{B}} \in[8.45,666]$. The reddish area illustrates the approximated region where croissants exist. Furthermore, there is a maximal initial offset $r_{\text {init }}$ above which overlapping with the vessel wall would occur.

The shape phase diagram in figure 6(a) (together with (b) and (c) explained below) constitutes our main result from the simulations. Starting near the channel center (in the reddish region) results in croissants, whereas higher initial offsets lead to slippers. The transition is found to be sharp, and depends significantly on the velocity. Croissants are the only stable steady state in a small region ranging from around 2 to $3 \mathrm{~mm} / \mathrm{s}$, independently of the initial radial position. Smaller and larger velocities tend to favor slippers. Stable croissants do not appear below $0.25 \mathrm{~mm} / \mathrm{s}$. In the case of the slippers, the final periodic state is usually reached after roughly 2 to $10 \mathrm{~s}$. In contrast, the final croissant state is sometimes achieved only after more than 10 to $30 \mathrm{~s}$, possibly after an intermediate slipper state that can last several seconds (see figure S4 and the movie in the supplementary information). Hence, shapes observed after less than one second often turn out to be transient, contrary to the interpretation of Ye et al. [54] but in agreement with Prado et al. [24].

Considering our results in figure 6(a) in more detail, we find that two different types of croissants and slippers are possible. On the one hand, at very low velocities $(\lesssim 0.7 \mathrm{~mm} / \mathrm{s})$ the slippers no longer exhibit tank-treading motion of the membrane and instead show tumbling behavior: The cell rotates around the $z$-axis while approximately preserving its shape (similar to a rigid-body, see the SI for a movie). The difference compared to the tumbling motion observed by Fedosov et al. [4] is that the cell still exhibits a clear slipper-like instead of a proper discocyte shape. Hence, we classify this mode still as slipper. On the other hand, at very high velocities $(\gtrsim 7 \mathrm{~mm} / \mathrm{s})$ slightly asymmetric shapes strongly reminiscent of croissants with a distinct tank-treading motion can sometimes be observed (see the inset in figure 6(c) for an example). As the shape itself is very close to a croissant, we will nevertheless consider it to be a croissant below.

A natural question that occurs in light of the profound bistability is the influence of other initial shapes on the result. To this end, we consider a typical croissant as well as a typical slipper as the starting shape. Both were obtained from previous simulations that started with the discocyte form and are depicted in the supplementary information. We once again construct the shape phase diagram as before and display the results in figures 6(b) and (c). Note that the different starting shapes admit a larger initial radial position $r_{\text {init }}$ of the centroid. In short, starting with a croissant favors croissants in the steady state (the reddish area is larger than in figure 6(a)). For slippers it is the other way around: Starting with a slipper tends to produce more slippers (reddish area smaller than in figure 6(a)). Despite this, the croissantonly region from around 2 to $3 \mathrm{~mm} / \mathrm{s}$ still exists unscathed. Overall, only two qualitative differences occur between the phase diagrams of different initial shapes, both at lower velocity when starting with the croissant shape (figure 6(b)): First, stable croissants emerge at very low velocities $(\lesssim 0.7 \mathrm{~mm} / \mathrm{s})$ and second, the croissant-only peak exhibits a "protrusion" into the slipper space. This observation suggests that slippers and croissants can be stable below $2 \mathrm{~mm} / \mathrm{s}$ for most $r_{\text {init }}$ values, although in some cases a very precise croissant configuration is required in order to actually get a croissant in the steady state.

Another interesting aspect concerns the radial positions of the centroids in the final steady states. The average values are obtained by computing the temporal average in the steady state first for each simulation, and then combining the results for identical shapes via a weighted arithmetic mean. We use the observation time in the steady state as the weight. This procedure leads to figure $7(\mathrm{a})$. Obviously, the final radial positions are 

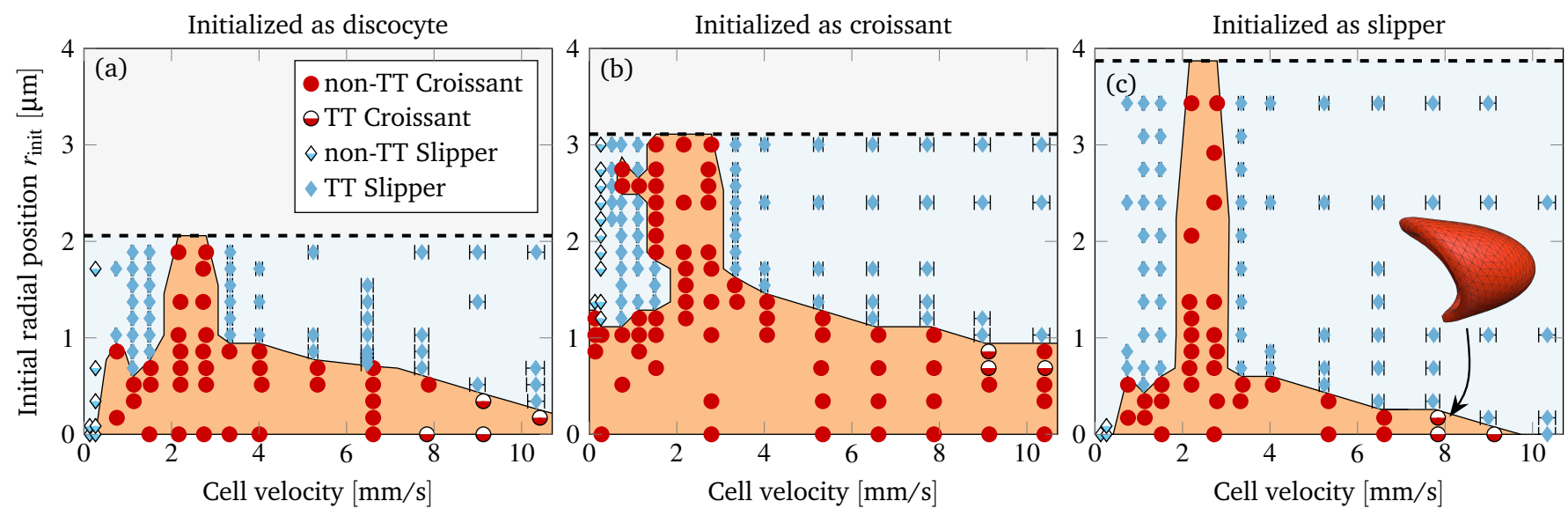

Figure 6. Simulation results: Shapes obtained when varying the initial offset $r_{\text {init }}$ and the velocity. Each symbol corresponds to one simulation. The horizontal axis shows the average cell velocity in the steady state, while horizontal error bars depict the minimal and maximal velocities in one period (variations for croissants nearly zero and thus not visible). The upper dashed line represents the maximal initial offset: Above this offset, the cell would overlap with the wall. The other lines and the colored areas are guides to the eye and illustrate the different regions in the phase diagram. Each figure corresponds to a different initial shape, namely (a) to the typical discocyte shape, (b) to a croissant and (c) to a slipper. These shapes are shown in figure 1(a) and in the SI. The inset in the last figure depicts an example of a tank-treading croissant. Figure 5 corresponds to the vertical column at $\approx 6.5 \mathrm{~mm} / \mathrm{s}$ in sub-figure (a).

independent of the initial starting shape, i.e. a particular steady state shape at a certain velocity is always located at the same position. Furthermore, non-tank-treading croissants are always almost centered, with only minor deviations away from zero. These slight deviations in the range from 2 to $4 \mathrm{~mm} / \mathrm{s}$ are mainly due to some croissants exhibiting minuscule periodic shape deformations. Moreover, the centroids of tank-treading croissants occurring at velocities $\gtrsim 8 \mathrm{~mm} / \mathrm{s}$ are located near but not directly in the center. Their slight off-centered position is a result of their asymmetry.

In contrast to croissants, slippers are located 0.8 to $1.5 \mu \mathrm{m}$ away from the channel's axis. The minimum position is attained for velocities near the border of the croissant-only region in the phase diagram (at around 2 and $3 \mathrm{~mm} / \mathrm{s}$, compare figure 6 ). Above, the off-center position increases and seems to converge to a value of around $1.5 \mu \mathrm{m}$. The reason for this increase is that slippers become more elongated and thinner at higher velocities (up to a certain degree), as shown in figure 7(b) and also observed in previous experiments [22]. Thus, they effectively become smaller in the radial direction and their centroids can move closer to the wall. We note that the distance between the wall and the upper side of the slipper approximately remains the same for all velocities. This also hints at that the "optimal" off-center position for the slippers is more than $1.5 \mu \mathrm{m}$ away from the center, and that this particular value is due to the smallness of the channel.

\section{COMPARISON BETWEEN EXPERIMENTS AND SIMULATIONS}

\section{A. Comparison of shapes}

Considering figure 1, the croissants obtained from simulations and experiments look very similar, although the experimental shapes appear to be somewhat larger. The reason is diffraction: The "true" cell border lies in the bright and not within the dark rim. However, the slippers appear to look qualitatively different. This is due to the high magnification and numerical aperture of the objective which results in a small depth of field of around $1 \mu \mathrm{m}$. Cell borders above and below the middle plane are therefore blurred out and become invisible while the mid-plane cut becomes dominant. Thus, for comparison we should use the middle cross-section of the numerically obtained shapes. Here we find good agreement (compare figure $1(\mathrm{~g})$ with (e)).

\section{B. Comparison of the phase diagrams}

A qualitative comparison between the phase diagrams of steady states from the experiments (fig. 3(a)) and the simulations (fig. 6) shows a striking resemblance: Both exhibit a distinct peak in the number of croissants at lower velocities (1 to $3 \mathrm{~mm} / \mathrm{s}$ ) at the expense of the number of slippers. The latter dominate the picture at high velocities $(>7 \mathrm{~mm} / \mathrm{s})$. At intermediate velocities both shapes coexist and can therefore be observed simultaneously in measurements. Moreover, the simulations at very low velocities showed croissants only if the initial 

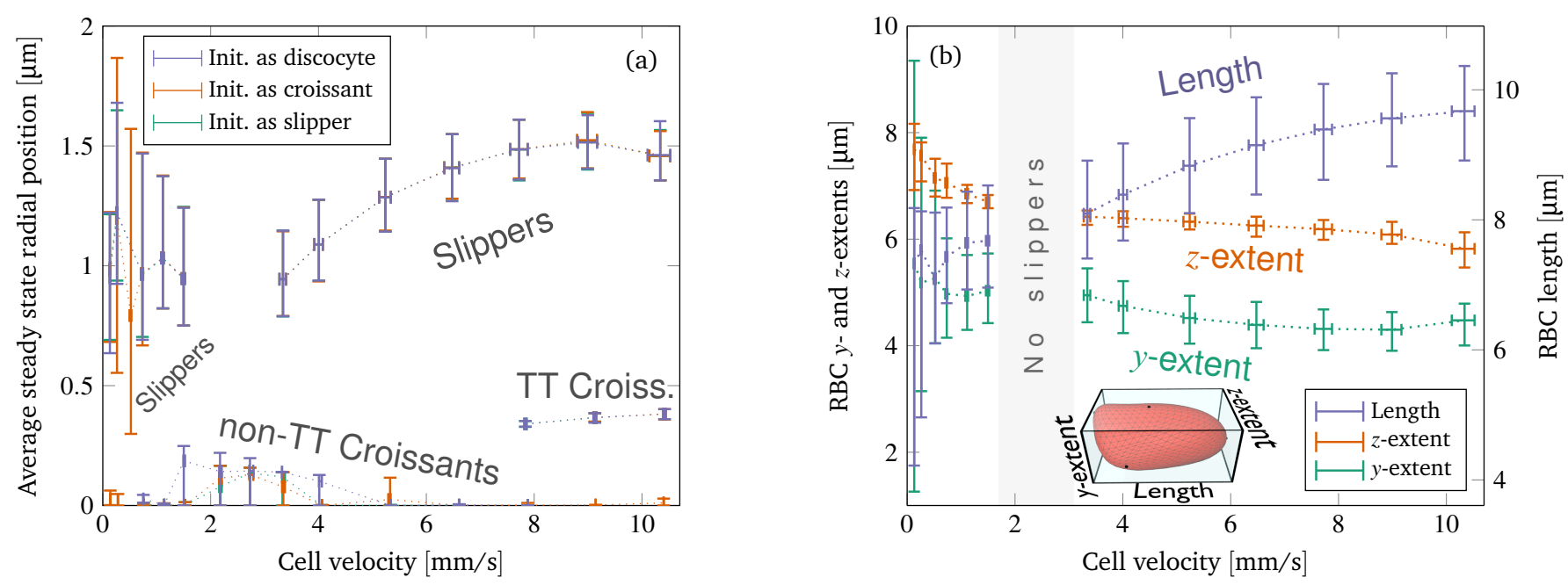

Figure 7. Simulation results: (a) Average radial positions of the steady states from figure 6 as a function of cell velocity for the three different starting shapes. The lower curves are for non-TT croissants and TT croissants, the upper curves are for (TT and non-TT) slippers. We show on the vertical axis the weighted temporal mean of the radial centroid position of RBCs that assume the same shapes. The vertical error bars depict the total minimal and maximal position, while the horizontal error bars show the total minimal and maximal cell velocities (in each period of the steady states, respectively). (b) Extents of the slipper shapes from figure (a) in the flow $(x$-)direction (length) and along the other two axes, as illustrated by the inset showing the channel-aligned bounding box around a slipper. The vertical error bars depict the minimum and maximum extents during the periodic contractions, while the horizontal error bars are the same as in (a).

$\mathrm{RBC}$ was already prepared in that state, meaning that in the experiments this shape is highly unexpected. Indeed, we were not able to clearly classify most of the observed shapes in that regime as either croissants or slippers.

Obtaining a direct quantitative comparison requires a translation of the numerical threshold in figure 6 (which is in terms of the initial offset) into a prediction regarding the fraction of shapes, because the experimental phase diagram is in terms of the observed fraction of shapes. This is done by counting the fraction of croissants entering the channel with an offset below the numerical threshold. This fraction corresponds directly to the predicted fraction of croissant shapes. More precisely, we first define $r_{\text {trans }}$ as the initial radial offset which separates croissants from slippers in the simulations by using the black line in figure 6 . An exception is the small croissant-only region (i.e. the interval of the topmost horizontal line in figure 6) where we take $r_{\text {trans }} \rightarrow \infty$. This is consistent with our interpretation that only croissants exist in this particular interval. One $r_{\text {trans }}$ is computed for each experimental cell velocity from figure 3 (a). Second, each radial position $r_{\text {trans }}$ is projected onto the $y$-axis to give $y_{\text {trans }}$ (see sec. II B) because only the $y$-offset is known from experiments. Third, from the experimental offset distribution at the channel entrance (figure 4) we can then estimate the fraction of cells $\phi$ that enter the channel with an offset below $y_{\text {trans. }}$. Accordingly, the simulations predict a fraction $\phi$ of croissants in the steady state. The value of $\phi$ can thus be directly compared with the experimental phase diagram from figure 3 (a). This is done once for every starting configuration employed in the simulations.

Figure 8 shows this key result of our contribution, i.e. the predicted fraction of croissants $\phi$ as a function of the cell velocity for each starting shape. The vertical error bars depict the uncertainty in the prediction, whose computation is explained in the supplementary information. They are comparably large in the croissant-only region because the experimental velocities lie very near its sharp boundary. The horizontal error bars illustrate the standard deviation $\sigma_{u}$ of the experimentally measured cell velocities. Clearly, we find very good agreement between the prediction from the simulation and the experimental observation when considering the slipper starting shape (figure 8(c)). Starting with a discocyte or croissant leads to slightly more pronounced deviations (figures 8(a) and (b)), but still a satisfactory semi-quantitative agreement is maintained. This suggests the intuitive conclusion that the starting shapes in the experiment are closer to the rather asymmetric slippers than to the highly symmetric discocytes or croissants. Indeed, as explicitly shown in the SI, we only observe non-classifiable and rather asymmetric "other" shapes at the channel entrance.

As mentioned in the introduction, experimental investigations with more detailed shape studies are rather scarce. A comparison of the phase diagrams with the experimental literature is therefore limited to rough qualitative statements. Tomaiuolo et al. [22] found croissants and "others" for a cell velocity of $1.1 \mathrm{~mm} / \mathrm{s}$ using $\lambda \approx 5$ in a cylindrical tube with diameter $10 \mu \mathrm{m}$. This is in agreement with our results. At $36 \mathrm{~mm} / \mathrm{s}$, slippers but also croissants have been observed. Since we cannot reach velocities that high, we can neither confirm nor refute the occurrence of the latter. Extrapolation of figure 8 is dangerous since the Reynolds number at $36 \mathrm{~mm} / \mathrm{s}$ is around $\mathrm{Re} \approx 0.24$ 

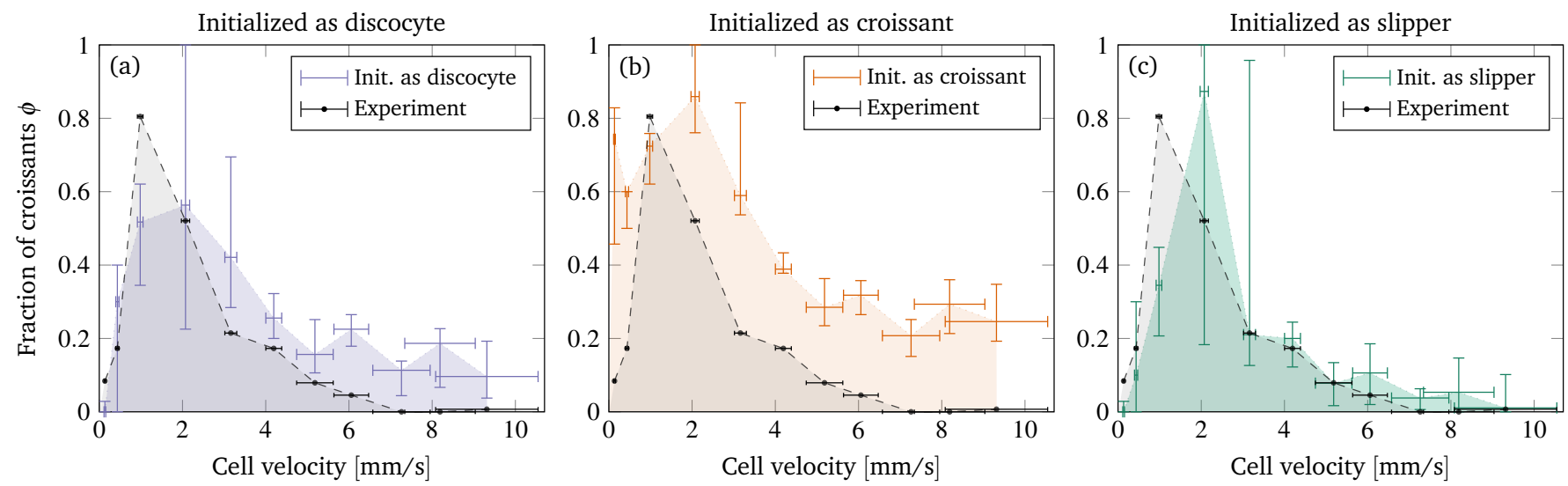

Figure 8. Fraction of croissants $\phi$ predicted by the simulations, once for each starting configuration employed in the simulations: (a) Simulations started with the typical discocyte, (b) with the croissant and (c) with the slipper shape. To allow for a direct comparison, we included the experimental results from figure 3(a) in each diagram (black dashed line). The horizontal error bars depict the standard deviation $\sigma_{u}$ of the measured cell velocities (as in figure 3(a)), while the vertical error bars show the uncertainty in the prediction as explained in the supplementary information. The lines and shaded areas serve as guides to the eye. See the main text for further details.

and thus inertia effects might have noticeable contributions [89, 90]. Continuing, Cluitmans et al. [25] found croissants and tumbling "others" at $1.1 \mathrm{~mm} / \mathrm{s}$ and slippers at $13.6 \mathrm{~mm} / \mathrm{s}$ in rectangular channels of $10 \mu \mathrm{m}$ and $7 \mu \mathrm{m}$ widths and a height of $10 \mu \mathrm{m}$, which is consistent with our results. The experimental phase diagram presented in references 21 and 20 also agrees with our results insofar that slippers occur at higher and croissants at lower velocities. Yet, the considered velocities were higher than $10 \mathrm{~mm} / \mathrm{s}$ and the viscosity ratio was $\lambda \lesssim 0.27$, i.e. much lower. Furthermore, figure 3 in reference 18 (cylindrical tube, $\lambda \approx 4$ ) also showed coexistence of croissants and slippers for velocities $\lesssim 1 \mathrm{~mm} / \mathrm{s}$ and only croissants roughly in the range $1-2 \mathrm{~mm} / \mathrm{s}$, matching approximately with our results.

Regarding previous numerical studies, Fedosov et al. [4] performed detailed 3D numerical simulations in cylindrical channels for $\lambda=1$. Taking a diameter of $10 \mu \mathrm{m}$ (translating into a confinement value of $\chi=0.65$ in their work), they varied the average velocity from around $0.05 \mathrm{~mm} / \mathrm{s}$ to $0.7 \mathrm{~mm} / \mathrm{s}$. They observed a transition from snaking, to tumbling, to tank-treading slippers and finally to parachutes (which are very similar to croissants). In our simulations we found tumbling and tank-treading slippers at velocities of the order of $0.1 \mathrm{~mm} / \mathrm{s}$, and an increasing frequency of croissants above. This matches at least qualitatively with Fedosov et al.'s results. However, they did not vary the initial condition.

\section{Comparison of cell positions}

Next, we compare the preferred position of the cells in the steady state. The simulations predict a centered positioning of croissants (figure $7(\mathrm{a})$ ), i.e. both the $y$ - and the $z$-offsets are nearly zero. This matches with figure $3(\mathrm{~b})$

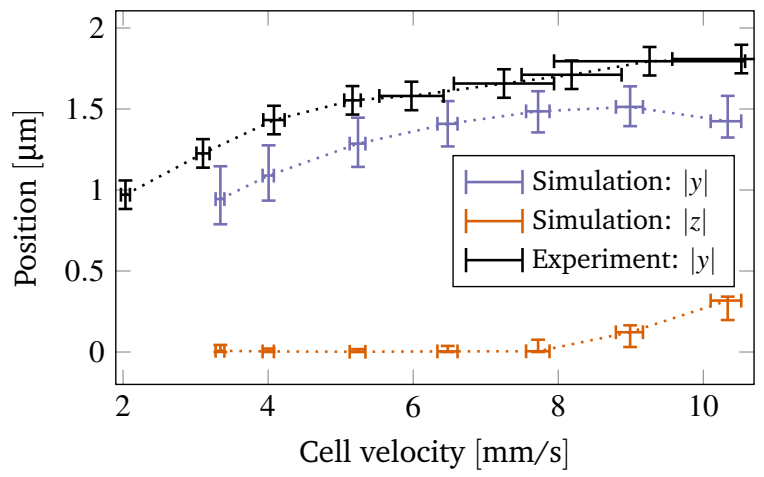

Figure 9. Comparison between the centroid positions from the simulations (absolute values of the $y$ - and $z$-coordinates) and experiments (absolute value of the $y$-coordinate) for cells that have a TT-slipper shape in the steady state. Error bars for the simulations as in figure $7(\mathrm{a})$. The horizontal error bars for the experimental data depict the standard deviation $\sigma_{u}$ of the cell velocities, while the vertical error bars represent the estimated uncertainty in the position determination.

where a very sharp peak at the channel center is found for the pressure drops within the croissant-peak region.

For slippers, the simulations showed an increase of the radial position of up to around $1.5 \mu \mathrm{m}$ (figure $7(\mathrm{a})$ ). Considering the $y$ - and $z$-coordinates separately in figure 9 , we see that $z \approx 0$ and the major offset happens in the $y$-direction. This is rather fortunate as the $y$-offset is also easily accessible in the experiments, contrary to the $z$-offset. As can be seen in the measured $y$-distribution (figure 3(b)), we have two off-centered peaks for slippers. Taking the distribution function for only the slippers, we extract the positions $y_{l}$ and $y_{r}$ of the two peaks. Exploiting the $\pm y$-symmetry of the channel, the off-centered position is then computed as $\left(y_{r}-y_{l}\right) / 2$, i.e. in essence as 
the average of the two peak distances to the central minimum. Figure 9 compares these values with the numerical results: The behavior is the same (an increase with velocity) and the predicted values show only a small systematic deviation of around $\approx 0.3 \mu \mathrm{m}$, i.e. of less than $4 \%$ of the $\mathrm{RBC}$ diameter $2 R_{\mathrm{RBC}}$. A possible reason is that the optically recorded boundaries of the $\mathrm{RBC}$ and the channel walls are somewhat blurry (compare the experimental images in figure 1).

\section{Implications of the comparison}

There has been quite some debate in the literature if the croissant (or parachute) shapes observed via light microscopy are indeed what they appear to be. Gaehtgens et al. [17] (fig. 4 therein), for example, solidified the flowing RBCs with glutaraldehyde and found that the croissant-like shapes were actually slipper-like. Skalak and Branemark [37] pointed out that such shapes can also be "edge-on" discocytes with a flattened back. Ultimately, to uniquely identify the forms one needs some method to record the full 3D geometry of the flowing cells (e.g. as in references $15,26,32,91-94)$. This is unfortunately very hard to implement in the present experimental setup. However, this missing information is complemented here by the numerical simulations which are in good agreement with the experiments and thus our interpretation of the shapes as croissants should be correct.

The good agreement furthermore implies that our red blood cell model and simulation method is fully appropriate for describing the flow of RBCs in a straight microchannel. More sophisticated methods including e.g. thermal fluctuations or surface viscosity $[4,24,52,53,95,96]$ are, at least for the present geometry, not required. For croissants this is intuitive since membrane movement such as tank-treading is absent, for the tank-treading slippers it is somewhat less obvious.

\section{SUMMARY \& CONCLUSION}

To summarize, we have performed in-vitro experiments and 3D simulations of healthy red blood cells flowing in a microchannel. The viscosity ratio was approximately 5 and the flow velocities ranged from around $0.1 \mathrm{~mm} / \mathrm{s}$ to $10 \mathrm{~mm} / \mathrm{s}$ in both methodologies, corresponding to the typical conditions prevailing in the microvascular system. We found that both the flow velocity as well as the initial starting configuration (offset from channel center, shape) have a major impact on the final steady state of the cells. Using three different starting shapes (discocyte, croissant, slipper), we constructed the corresponding phase diagrams via simulations. In most cases the cells assumed one out of two different forms: either a centered croissant or an off-centered slipper. Interestingly, for most velocities bistability, i.e. a dependence of the final shape on the initial position, was observed. Only in a small range of velocities (at around $\approx 1 \mathrm{~mm} / \mathrm{s}$ ) was the final shape found to be always a croissant. The experimental diagram showed very good agreement with the numerical result, especially when considering the simulations that used the rather asymmetric slipper as starting shape.

We thus conclude that the employed numerical RBC model can sensibly describe the cell behavior in the presented setup. Moreover, since we used physiological viscosity ratios and flow velocities, we speculate that croissants and slippers can occur in the microvasculature at the same set of system parameters not just as transients but rather that both are states which are intrinsically assumed by the cells. Our results are important for applications where the cells should be in a specific state (e.g. in lab-ona-chip devices) and allow for a comprehensive validation of numerical models.

\section{CONFLICTS OF INTEREST}

There are no conflicts to declare.

\section{ACKNOWLEDGMENTS}

A. Guckenberger and A. Kihm contributed equally to this work. S. Gekle and C. Wagner contributed equally to this work.

Funding from the Volkswagen Foundation and computing time granted by the Leibniz-Rechenzentrum on SuperMUC are gratefully acknowledged by A. Guckenberger and S. Gekle. A. Kihm, T. John and C. Wagner kindly acknowledge the support and funding of the "Deutsch-Französische-Hochschule" (DFH) DFDK "Living Fluids".
[1] J. B. Freund, "The flow of red blood cells through a narrow spleen-like slit," Phys. Fluids 25, 110807 (2013).

[2] J. Picot, P. A. Ndour, S. D. Lefevre, W. El Nemer, H. Tawfik, J. Galimand, L. Da Costa, J.-A. Ribeil, M. de Montalembert, V. Brousse, B. Le Pioufle, P. Buffet, C. Le Van Kim, and O. Français, "A biomimetic microfluidic chip to study the circulation and mechanical retention of red blood cells in the spleen," Am. J. Hematol.
90, 339 (2015).

[3] S. Salehyar and Q. Zhu, "Deformation and internal stress in a red blood cell as it is driven through a slit by an incoming flow," Soft Matter 12, 3156 (2016).

[4] D. A. Fedosov, M. Peltomäki, and G. Gompper, "Deformation and dynamics of red blood cells in flow through cylindrical microchannels," Soft Matter 10, 4258 (2014). 
[5] O. Aouane, M. Thiébaud, A. Benyoussef, C. Wagner, and C. Misbah, "Vesicle dynamics in a confined Poiseuille flow: From steady state to chaos," Phys. Rev. E 90, 033011 (2014).

[6] N. Tahiri, T. Biben, H. Ez-Zahraouy, A. Benyoussef, and C. Misbah, "On the problem of slipper shapes of red blood cells in the microvasculature," Microvasc. Res. 85, 40 (2013).

[7] V. Vitkova, M.-A. Mader, B. Polack, C. Misbah, and T. Podgorski, "Micro-Macro Link in Rheology of Erythrocyte and Vesicle Suspensions," Biophys. J. 95, L33 (2008).

[8] D. A. Fedosov, W. Pan, B. Caswell, G. Gompper, and G. E. Karniadakis, "Predicting human blood viscosity in silico," Proc. Natl. Acad. Sci. 108, 11772 (2011).

[9] T. Krüger, M. Gross, D. Raabe, and F. Varnik, "Crossover from tumbling to tank-treading-like motion in dense simulated suspensions of red blood cells," Soft Matter 9, 9008 (2013).

[10] M. Thiébaud, Z. Shen, J. Harting, and C. Misbah, "Prediction of Anomalous Blood Viscosity in Confined Shear Flow," Phys. Rev. Lett. 112, 238304 (2014).

[11] D. Katanov, G. Gompper, and D. A. Fedosov, "Microvascular blood flow resistance: Role of red blood cell migration and dispersion," Microvasc. Res. 99, 57 (2015).

[12] L. Lanotte, J. Mauer, S. Mendez, D. A. Fedosov, J.-M. Fromental, V. Claveria, F. Nicoud, G. Gompper, and M. Abkarian, "Red cells' dynamic morphologies govern blood shear thinning under microcirculatory flow conditions," Proc. Natl. Acad. Sci. 113, 13289 (2016).

[13] E. Henry, S. H. Holm, Z. Zhang, J. P. Beech, J. O. Tegenfeldt, D. A. Fedosov, and G. Gompper, "Sorting cells by their dynamical properties," Sci. Rep. 6, 34375 (2016).

[14] O. Otto, P. Rosendahl, A. Mietke, S. Golfier, C. Herold, D. Klaue, S. Girardo, S. Pagliara, A. Ekpenyong, A. Jacobi, M. Wobus, N. Töpfner, U. F. Keyser, J. Mansfeld, E. Fischer-Friedrich, and J. Guck, "Real-time deformability cytometry: On-the-fly cell mechanical phenotyping," Nat. Methods 12, 199 (2015).

[15] F. Merola, P. Memmolo, L. Miccio, R. Savoia, M. Mugnano, A. Fontana, G. D'Ippolito, A. Sardo, A. Iolascon, A. Gambale, and P. Ferraro, "Tomographic Flow Cytometry by Digital Holography," Light Sci. Appl. 6, e16241 (2017).

[16] A. Farutin and C. Misbah, "Symmetry breaking and crossstreamline migration of three-dimensional vesicles in an axial Poiseuille flow," Phys. Rev. E 89, 042709 (2014).

[17] P. Gaehtgens, C. Dührssen, and K. H. Albrecht, "Motion, deformation, and interaction of blood cells and plasma during flow through narrow capillary tubes," Blood Cells 6, 799 (1980).

[18] Y. Suzuki, N. Tateishi, M. Soutani, and N. Maeda, "Deformation of Erythrocytes in Microvessels and Glass Capillaries: Effects of Erythrocyte Deformability," Microcirculation 3, 49 (1996).

[19] T. W. Secomb, B. Styp-Rekowska, and A. R. Pries, "TwoDimensional Simulation of Red Blood Cell Deformation and Lateral Migration in Microvessels," Ann. Biomed. Eng. 35, 755 (2007).

[20] M. Faivre, Drops, Vesicles and Red Blood Cells: Deformability and Behavior under Flow, Ph.D. thesis, Université Joseph-Fourier - Grenoble I, Grenoble (2006).

[21] M. Abkarian, M. Faivre, R. Horton, K. Smistrup, C. A. Best-Popescu, and H. A. Stone, "Cellular-scale hydrody- namics," Biomed. Mater. 3, 034011 (2008).

[22] G. Tomaiuolo, M. Simeone, V. Martinelli, B. Rotoli, and S. Guido, "Red blood cell deformation in microconfined flow," Soft Matter 5, 3736 (2009).

[23] G. Tomaiuolo and S. Guido, "Start-up shape dynamics of red blood cells in microcapillary flow," Microvasc. Res. 82, 35 (2011).

[24] G. Prado, A. Farutin, C. Misbah, and L. Bureau, "Viscoelastic Transient of Confined Red Blood Cells," Biophys. J. 108, 2126 (2015).

[25] J. C. A. Cluitmans, V. Chokkalingam, A. M. Janssen, R. Brock, W. T. S. Huck, and G. J. C. G. M. Bosman, "Alterations in Red Blood Cell Deformability during Storage: A Microfluidic Approach," BioMed Res. Int. 2014, e764268 (2014).

[26] S. Quint, A. F. Christ, A. Guckenberger, S. Himbert, L. Kaestner, S. Gekle, and C. Wagner, "3D tomography of cells in micro-channels," Appl. Phys. Lett. 111, 103701 (2017).

[27] R. M. Hochmuth, R. N. Marple, and S. P. Sutera, "Capillary blood flow: I. Erythrocyte deformation in glass capillaries," Microvascular Research 2, 409 (1970).

[28] V. Seshadri, R. M. Hochmuth, P. A. Croce, and S. P. Sutera, "Capillary blood flow: III. Deformable model cells compared to erythrocytes in vitro," Microvascular Research 2, 434 (1970).

[29] V. P. Zharov, E. I. Galanzha, Y. Menyaev, and V. V. Tuchin, "In vivo high-speed imaging of individual cells in fast blood flow," J. Biomed. Opt 11, 054034 (2006).

[30] G. Tomaiuolo, V. Preziosi, M. Simeone, S. Guido, R. Ciancia, V. Martinelli, C. Rinaldi, and B. Rotoli, "A methodology to study the deformability of red blood cells flowing in microcapillaries in vitro," Ann. Ist. Super. Sanità 43 186 (2007).

[31] S. Guido and G. Tomaiuolo, "Microconfined flow behavior of red blood cells in vitro," Comptes Rendus Phys. 10, 751 (2009).

[32] S. S. Gorthi and E. Schonbrun, "Phase imaging flow cytometry using a focus-stack collecting microscope," Opt. Lett. 37, 707 (2012).

[33] L. Lanotte, G. Tomaiuolo, C. Misbah, L. Bureau, and S. Guido, "Red blood cell dynamics in polymer brushcoated microcapillaries: A model of endothelial glycocalyx in vitro," Biomicrofluidics 8, 014104 (2014).

[34] G. Tomaiuolo, L. Lanotte, R. D'Apolito, A. Cassinese, and S. Guido, "Microconfined flow behavior of red blood cells," Med. Eng. Phys. 38, 11 (2016).

[35] V. Clavería, O. Aouane, M. Thiébaud, M. Abkarian, G. Coupier, C. Misbah, T. John, and C. Wagner, "Clusters of red blood cells in microcapillary flow: Hydrodynamic versus macromolecule induced interaction," Soft Matter 12, 8235 (2016).

[36] M. M. Guest, T. P. Bond, R. G. Cooper, and J. R. Derrick, "Red Blood Cells: Change in Shape in Capillaries," Science 142, 1319 (1963).

[37] R. Skalak and P. I. Branemark, "Deformation of Red Blood Cells in Capillaries," Science 164, 717 (1969).

[38] K. Kubota, J. Tamura, T. Shirakura, M. K Imura, K. Y Amanaka, T. Isozaki, and I. Nishio, "The behaviour of red cells in narrow tubes in vitro as a model of the microcirculation," Br. J. Haematol. 94, 266 (1996).

[39] G. Tomaiuolo, L. Lanotte, G. Ghigliotti, C. Misbah, and S. Guido, "Red blood cell clustering in Poiseuille microcapillary flow," Phys. Fluids 24, 051903 (2012). 
[40] C. Wagner, P. Steffen, and S. Svetina, "Aggregation of red blood cells: From rouleaux to clot formation," Comptes Rendus Physique Living fluids / Fluides vivants, 14, 459 (2013).

[41] M. Brust, O. Aouane, M. Thiébaud, D. Flormann, C. Verdier, L. Kaestner, M. W. Laschke, H. Selmi, A. Benyoussef, T. Podgorski, G. Coupier, C. Misbah, and C. Wagner, "The plasma protein fibrinogen stabilizes clusters of red blood cells in microcapillary flows," Sci. Rep. 4, 4348 (2014).

[42] H. L. Goldsmith and J. Marlow, "Flow Behaviour of Erythrocytes. I. Rotation and Deformation in Dilute Suspensions," Proc. R. Soc. Lond. B Biol. Sci. 182, 351 (1972).

[43] T. W. Secomb, R. Skalak, N. Özkaya, and J. F. Gross, "Flow of axisymmetric red blood cells in narrow capillaries," J. Fluid Mech. 163, 405 (1986).

[44] T. W. Secomb, "Flow-dependent rheological properties of blood in capillaries," Microvascular Research 34, 46 (1987).

[45] T. W. Secomb, R. Hsu, and A. R. Pries, "Motion of red blood cells in a capillary with an endothelial surface layer: Effect of flow velocity," Am. J. Physiol. - Heart Circ. Physiol. 281, H629 (2001).

[46] T. W. Secomb and R. Skalak, "A two-dimensional model for capillary flow of an asymmetric cell," Microvascular Research 24, 194 (1982).

[47] B. Kaoui, G. Biros, and C. Misbah, "Why Do Red Blood Cells Have Asymmetric Shapes Even in a Symmetric Flow?" Phys. Rev. Lett. 103, 188101 (2009).

[48] B. Kaoui, N. Tahiri, T. Biben, H. Ez-Zahraouy, A. Benyoussef, G. Biros, and C. Misbah, "Complexity of vesicle microcirculation," Phys. Rev. E 84, 041906 (2011).

[49] B. Kaoui, T. Krüger, and J. Harting, "How does confinement affect the dynamics of viscous vesicles and red blood cells?" Soft Matter 8, 9246 (2012).

[50] L. Shi, T.-W. Pan, and R. Glowinski, "Deformation of a single red blood cell in bounded Poiseuille flows," Phys. Rev. E 85, 016307 (2012), 10.1103/PhysRevE.85.016307.

[51] G. R. Lázaro, A. Hernández-Machado, and I. Pagonabarraga, "Rheology of red blood cells under flow in highly confined microchannels: I. effect of elasticity," Soft Matter 10, 7195 (2014).

[52] H. Noguchi and G. Gompper, "Shape transitions of fluid vesicles and red blood cells in capillary flows," Proc. Natl. Acad. Sci. 102, 14159 (2005).

[53] J. L. McWhirter, H. Noguchi, and G. Gompper, "Deformation and clustering of red blood cells in microcapillary flows," Soft Matter 7, 10967 (2011).

[54] T. Ye, H. Shi, L. Peng, and Y. Li, "Numerical studies of a red blood cell in rectangular microchannels," J. Appl. Phys. 122, 084701 (2017).

[55] B. Kaoui, G. Coupier, C. Misbah, and T. Podgorski, "Lateral migration of vesicles in microchannels: Effects of walls and shear gradient," Houille Blanche , 112 (2009).

[56] D. Cordasco, A. Yazdani, and P. Bagchi, "Comparison of erythrocyte dynamics in shear flow under different stressfree configurations," Phys. Fluids 26, 041902 (2014).

[57] Z. Peng, A. Mashayekh, and Q. Zhu, "Erythrocyte responses in low-shear-rate flows: Effects of non-biconcave stress-free state in the cytoskeleton," J. Fluid Mech. 742, 96 (2014).

[58] K. Sinha and M. D. Graham, "Dynamics of a single red blood cell in simple shear flow," Phys. Rev. E 92, 042710 (2015).
[59] G. R. Cokelet and H. J. Meiselman, "Rheological Comparison of Hemoglobin Solutions and Erythrocyte Suspensions," Science 162, 275 (1968).

[60] A. S. Popel and P. C. Johnson, "Microcirculation and Hemorheology," Annu. Rev. Fluid Mech. 37, 43 (2005).

[61] B. Cui, H. Diamant, and B. Lin, "Screened Hydrodynamic Interaction in a Narrow Channel," Phys. Rev. Lett. 89, 188302 (2002).

[62] H. Diamant, "Hydrodynamic Interaction in Confined Geometries," J. Phys. Soc. Jpn. 78, 041002 (2009).

[63] A. Koller, B. Dawant, A. Liu, A. S. Popel, and P. C. Johnson, "Quantitative analysis of arteriolar network architecture in cat sartorius muscle," Am. J. Physiol. - Heart Circ. Physiol. 253, H154 (1987).

[64] E. Evans and Y.-C. Fung, "Improved measurements of the erythrocyte geometry," Microvasc. Res. 4, 335 (1972).

[65] D.-V. Le, "Subdivision elements for large deformation of liquid capsules enclosed by thin shells," Comput. Methods Appl. Mech. Eng. 199, 2622 (2010).

[66] S. Chien, S. Usami, H. M. Taylor, J. L. Lundberg, and M. I. Gregersen, "Effects of hematocrit and plasma proteins on human blood rheology at low shear rates." J. Appl. Physiol. 21, 81 (1966).

[67] R. Skalak, N. Ozkaya, and T. C. Skalak, "Biofluid Mechanics," Annu. Rev. Fluid Mech. 21, 167 (1989).

[68] T. W. Secomb, "Blood Flow in the Microcirculation," Annu. Rev. Fluid Mech. 49, 443 (2017).

[69] Y. Kim, H. Shim, K. Kim, H. Park, S. Jang, and Y. Park, "Profiling individual human red blood cells using commonpath diffraction optical tomography," Sci. Rep. 4, 6659 (2014).

[70] R. Skalak, A. Tozeren, R. P. Zarda, and S. Chien, "Strain Energy Function of Red Blood Cell Membranes," Biophys. J. 13, 245 (1973).

[71] T. Krüger, F. Varnik, and D. Raabe, "Efficient and accurate simulations of deformable particles immersed in a fluid using a combined immersed boundary lattice Boltzmann finite element method," Comput. Math. Appl. 61, 3485 (2011).

[72] Y.-Z. Yoon, J. Kotar, G. Yoon, and P. Cicuta, "The nonlinear mechanical response of the red blood cell," Phys. Biol. 5, 036007 (2008).

[73] J. B. Freund, "Numerical Simulation of Flowing Blood Cells," Annu. Rev. Fluid Mech. 46, 67 (2014).

[74] P. B. Canham, "The minimum energy of bending as a possible explanation of the biconcave shape of the human red blood cell," J. Theor. Biol. 26, 61 (1970).

[75] W. Helfrich, "Elastic Properties of Lipid Bilayers: Theory and Possible Experiments," Z. Naturforsch. C 28, 693 (1973).

[76] A. Guckenberger and S. Gekle, "Theory and algorithms to compute Helfrich bending forces: A review," J. Phys. Condens. Matter 29, 203001 (2017).

[77] Y. Park, C. A. Best, K. Badizadegan, R. R. Dasari, M. S. Feld, T. Kuriabova, M. L. Henle, A. J. Levine, and G. Popescu, "Measurement of red blood cell mechanics during morphological changes," Proc. Natl. Acad. Sci. 107, 6731 (2010).

[78] A. Guckenberger, M. P. Schraml, P. G. Chen, M. Leonetti, and S. Gekle, "On the bending algorithms for soft objects in flows," Comput. Phys. Comm. 207, 1 (2016).

[79] A. Farutin, T. Biben, and C. Misbah, "3D numerical simulations of vesicle and inextensible capsule dynamics," J. Comput. Phys. 275, 539 (2014). 
[80] A. Guckenberger and S. Gekle, "A boundary integral method with volume-changing objects for ultrasoundtriggered margination of microbubbles," arXiv:1608.05196 [physics] (2017), arXiv:1608.05196 [physics].

[81] C. Pozrikidis, "Interfacial Dynamics for Stokes Flow," J. Comput. Phys. 169, 250 (2001).

[82] H. Zhao, A. H. Isfahani, L. N. Olson, and J. B. Freund, "A spectral boundary integral method for flowing blood cells," J. Comput. Phys. 229, 3726 (2010).

[83] D. Saintillan, E. Darve, and E. S. G. Shaqfeh, "A smooth particle-mesh Ewald algorithm for Stokes suspension simulations: The sedimentation of fibers," Phys. Fluids 17, 033301 (2005).

[84] Y. Saad and M. Schultz, "GMRES: A Generalized Minimal Residual Algorithm for Solving Nonsymmetric Linear Systems," SIAM J. Sci. Stat. Comput. 7, 856 (1986).

[85] P. Bogacki and L. F. Shampine, "A 3(2) pair of Runge Kutta formulas," Appl. Math. Lett. 2, 321 (1989).

[86] A. Daddi-Moussa-Ider, A. Guckenberger, and S. Gekle, "Long-lived anomalous thermal diffusion induced by elastic cell membranes on nearby particles," Phys. Rev. E 93, 012612 (2016).

[87] A. R. Pries, T. W. Secomb, and P. Gaehtgens, "Structure and hemodynamics of microvascular networks: Heterogeneity and correlations," Am. J. Physiol. - Heart Circ. Physiol. 269, H1713 (1995).

[88] O. Baskurt, B. Neu, and H. Meiselman, Red Blood Cell Aggregation (CRC Press, 2011).

[89] B. Kaoui and J. Harting, "Two-dimensional lattice Boltzmann simulations of vesicles with viscosity contrast," Rheol Acta 55, 465 (2016).

[90] C. Schaaf and H. Stark, "Inertial migration and axial control of deformable capsules," Soft Matter 13, 3544 (2017).

[91] N. C. Pégard and J. W. Fleischer, "Three-dimensional deconvolution microfluidic microscopy using a tilted channel," J. Biomed. Opt. 18, 040503 (2013).

[92] N. C. Pégard, M. L. Toth, M. Driscoll, and J. W. Fleischer, "Flow-scanning optical tomography," Lab Chip 14, 4447 (2014).

[93] V. K. Jagannadh, M. D. Mackenzie, P. Pal, A. K. Kar, and S. S. Gorthi, "Slanted channel microfluidic chip for $3 D$ fluorescence imaging of cells in flow," Opt. Express 24, 22144 (2016).

[94] K. Kim, K. Choe, I. Park, P. Kim, and Y. Park, "Holographic intravital microscopy for 2-D and 3-D imaging intact circulating blood cells in microcapillaries of live mice," Sci. Rep. 6, 33084 (2016).

[95] G. Tomaiuolo, M. Barra, V. Preziosi, A. Cassinese, B. Rotoli, and S. Guido, "Microfluidics analysis of red blood cell membrane viscoelasticity," Lab Chip 11, 449 (2011).

[96] A. Yazdani and P. Bagchi, "Influence of membrane viscosity on capsule dynamics in shear flow," J. Fluid Mech. 718, 569 (2013). 


\title{
Supplementary information for \\ "Numerical-experimental observation of shape bistability of red blood cells flowing in a microchannel"
}

\author{
Achim Guckenberger, Alexander Kihm, ${ }^{\mathrm{b}}$ Thomas John, ${ }^{\mathrm{b}}$ Christian Wagner, ${ }^{\mathrm{bc}}$ Stephan Gekle ${ }^{\mathrm{a}}$
}

Dated: November 19, 2017

\section{Contents}

S1 Croissant and slipper initial shapes $\quad 1$

S2 Time evolution details $\quad 2$

S3 About the error bars in the prediction 3

S4 Additional experimental data $\quad 5$

S5 References $\quad 5$

$\begin{array}{ll}\text { S6 Raw experimental images at } x=10 \mathrm{~mm} & 7\end{array}$

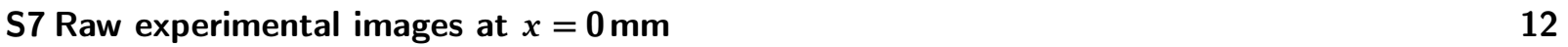

\section{S1 Croissant and slipper initial shapes}

Figure S1 shows the employed red blood cell (RBC) shapes when the initial shape is taken to be a croissant or slipper. These shapes were obtained from a previous simulation where we started with the typical discocyte shape. Figure S2 depicts the corresponding simulation setups, which are identical to the one from the main text except for the different RBC shape. Especially note that the initial radial offset $r_{\text {init }}$ of the centroid is along the same line. We always use the same croissant or slipper shape, regardless of the value of $r_{\text {init }}$.

(a)

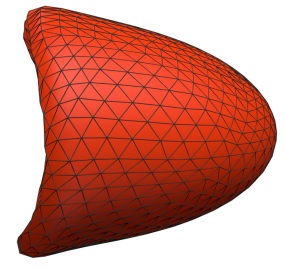

(b)

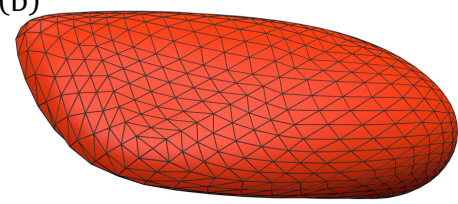

(c)

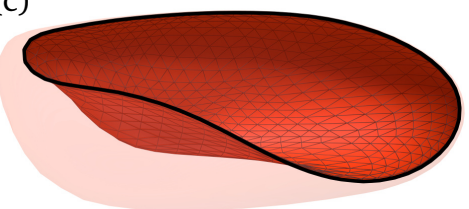

Figure S1: Employed initial shapes in the simulations when starting as a (a) croissant or (b) slipper. Figure (c) shows the cross-section of the slipper from (b). The black lines on the surfaces represent the used mesh.

\footnotetext{
${ }^{a}$ Biofluid Simulation and Modeling, Fachbereich Physik, Universität Bayreuth, Bayreuth

${ }^{b}$ Experimental Physics, Saarland University, 66123, Saarbrücken, Germany

${ }^{\mathrm{c}}$ Physics and Materials Science Research Unit, University of Luxembourg, Luxembourg, Luxembourg
} 

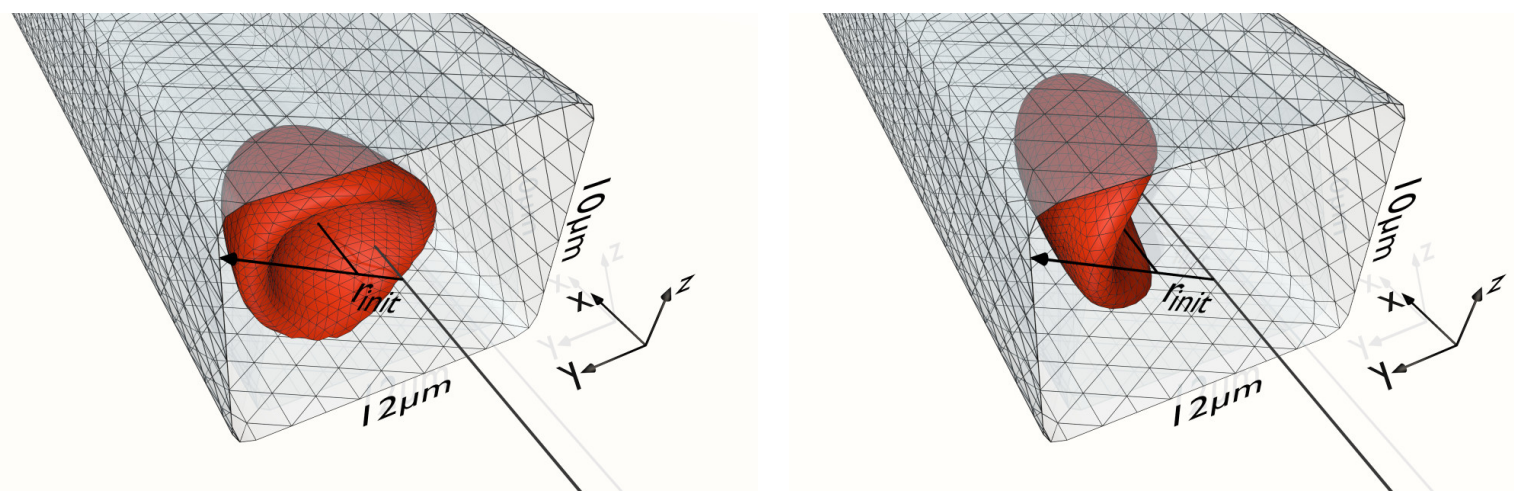

Figure S2: The simulation setups when starting with a croissant (left) or a slipper shape (right), similar to figure 2 from the main text. The cell shapes are the ones from figure S1.

\section{S2 Time evolution details}

As noted in the main text and shown in the TTSlipper supplementary video, the tank-treading (TT) slipper exhibits oscillatory contractions. These result in periodic variations of the radial position and the cell velocity, as exemplified in figure S3. This figure also illustrates how we extract the average, minimal and maximal values after reaching the steady state. The simulation results from the main text depict the average values as the main data points and the minimal and maximal values via error bars. Note that we do the same for the other shapes, although the resulting error bars are too small to be seen in the figures.
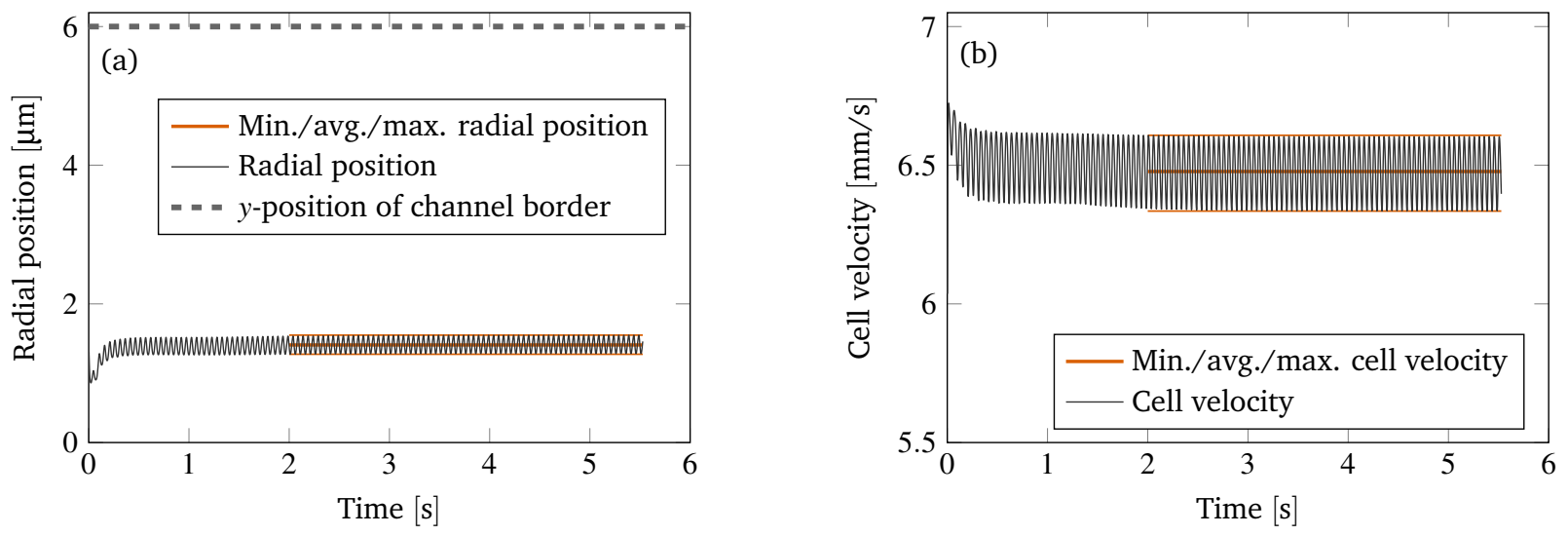

Figure S3: Time evolution of (a) the radial position and (b) the cell velocity for a slipper shape. The data is for the numerical simulation with $r_{\text {init }}=1.2 \mu \mathrm{m}$ from figure 5 in the main text. The orange lines show from bottom to top the minimum, average and maximum values that are extracted in the steady state, which is taken to begin at $2 \mathrm{~s}$ in this particular example.

Furthermore, reaching the steady state often takes a few seconds. Convergence into the croissant shape usually takes longer than reaching a steady slipper state. This is illustrated in figure S4(a) where we show for each simulation from figure 6 in the main text the approximated time until the steady state is reached. This time is the duration measured from the start of the simulations until the position, shape, velocity and deformation of the cells no longer change or become periodic. The longest times are observed when the velocity lies in the croissant-only range. An example for such a case is displayed in figure S4(b): For around eight seconds, the cell is in an almost periodic slipper state before moving to the center and becoming a croissant. However, after another four seconds some membrane rotation occurs, i.e. the RBC dimples (which are special points due to the discocyte reference state) move to a slightly different location. This results in a short lived and slightly off-centered position. After a total time of around $14 \mathrm{~s}$ the cell is in the final croissant state, with no movement occurring anymore. See the video LongCroissant for an illustration. 

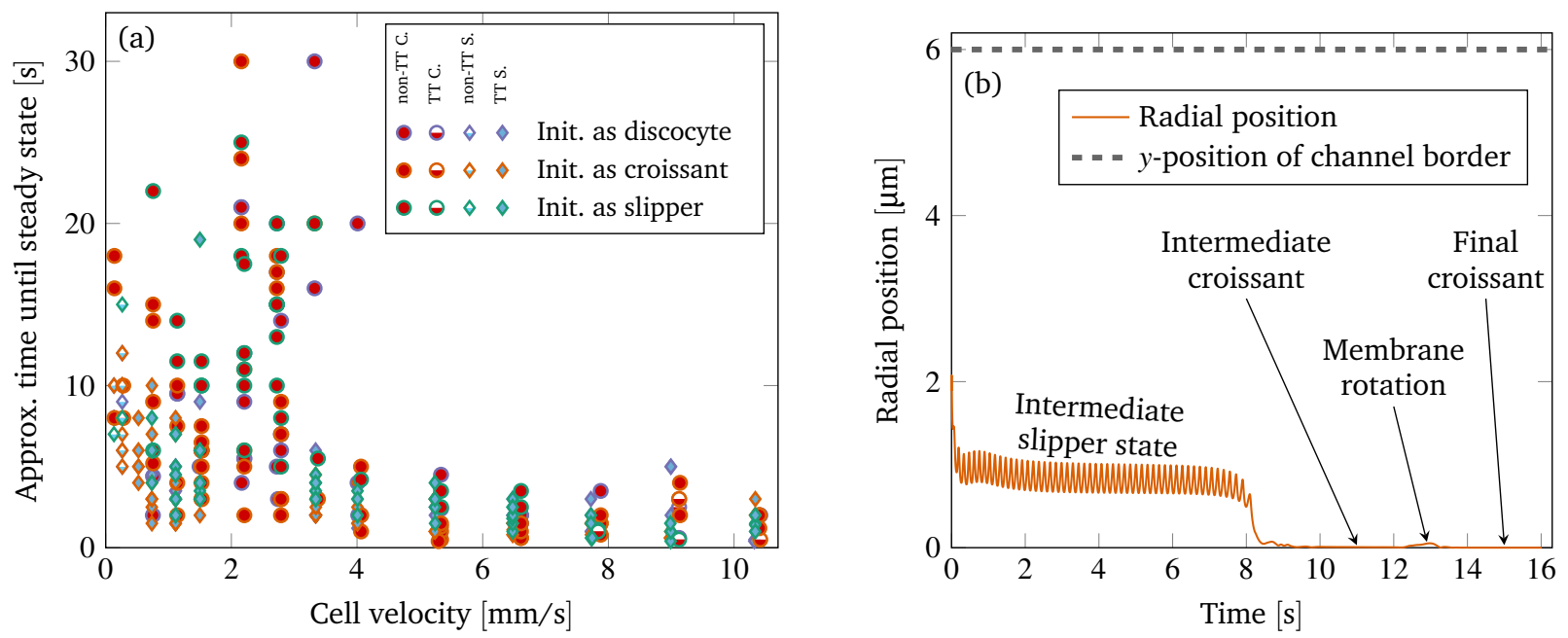

Figure S4: (a) Estimates of the time it takes for the cells to reach the steady state. The figure shows this time for all simulations from the three diagrams from figure 6 in the main text, where the cell was initialized as discocyte, croissant and slipper, respectively. These three initial shapes are indicated by the purple, orange and green borders around the symbols (see the three rows in the legend). The final steady state shapes (non-tank-treading croissant, tank-treading croissant, non-tank-treading slipper and tank-treading slipper) are represented by the same symbols as in the main text (compare the four columns in the legend). (b) Time evolution of the radial position of a cell which is initially in the discocyte state with $r_{\text {init }} \approx 1.89 \mu \mathrm{m}$ and has an average velocity of $\approx 2.79 \mathrm{~mm} / \mathrm{s}$ in the steady state (i.e. it lies in the croissant-only region). The steady state begins at around $14 \mathrm{~s}$. See the movie LongCroissant for a 3D visualization.

\section{S3 About the error bars in the prediction}

The determination of the vertical error bars in the comparison between experiments and simulations (figure 8 in the main text) consists of several steps that will be described in the following. To this end, consider figure S5. This figure shows exemplarily the numerical phase diagram when the starting shape is the discocyte, i.e. the symbols that indicate the steady states are identical to figure 6(a) from the main text. The middle gray line represents the position of the approximated transition threshold $r_{\text {trans }}$ between croissants and slippers, which was obtained by averaging the values from the adjacent simulation symbols.

The first step in the determination of the vertical error bars is to compute a lower and upper bound for the transition threshold. We do this by drawing a line through the highest croissant and lowest slipper symbols. This leads to the lower violet and upper green lines in figure S5. Thus, these two lines represent the uncertainty of the transition, which is a result of the finite distance between the simulations.

An exception in the construction of the three lines occurs in the region where the simulations predict only croissants. Due to the particular starting shape, there is a maximal initial offset. Experimentally, however, it is of course possible that the cells at the channel entrance have a larger offset (i.e. one that lies above the black dashed line in figure S5). Since the results from the simulations indicate that only croissants really exist in this region (regardless of the initial shape and offset), we take $r_{\text {trans }} \rightarrow \infty$. That way we predict a value of 1 for the fraction of croissants.

Second, we need to evaluate the transition lines at the experimental velocities. However, the measured velocities have not only an average $u$ but also a certain standard deviation $\sigma_{u} . \sigma_{u}$ is taken as the uncertainty in the velocity here. Evaluating the middle gray line at the average velocity $u$ results in the "best guess for $r_{\text {trans" }}$ (the circular symbols in figure S5). This value is then directly converted into the predicted fraction of croissants $\phi$ as described in the main text (via conversion to $y_{\text {trans }}$ and the measured offset distribution at the channel entrance). For the vertical error bars, we evaluate the three numerical transition lines (lower, middle and upper, i.e. violet, gray and green) at the three velocities $u, u-\sigma_{u}$ and $u+\sigma_{u}$, leading to nine values for $r_{\text {trans. }}$. The ones that will yield the lowest and largest fraction of croissants are shown as triangular symbols in figure S5 (the "lowest guess for $r_{\text {trans }}$ " and the "largest guess for $r_{\text {trans }}$ ").

Third, the predicted fractions of croissants are computed from the offset distribution at the channel entrance for each of these nine $r_{\text {trans }}$ values (as described in the main text), and additionally for $r_{\text {trans }} \pm s_{\mathrm{p}}$. This takes into account the uncertainty in the offset distribution due to the uncertainty $s_{\mathrm{P}}$ in the position measurement. As a result, we now have 27 predictions. 


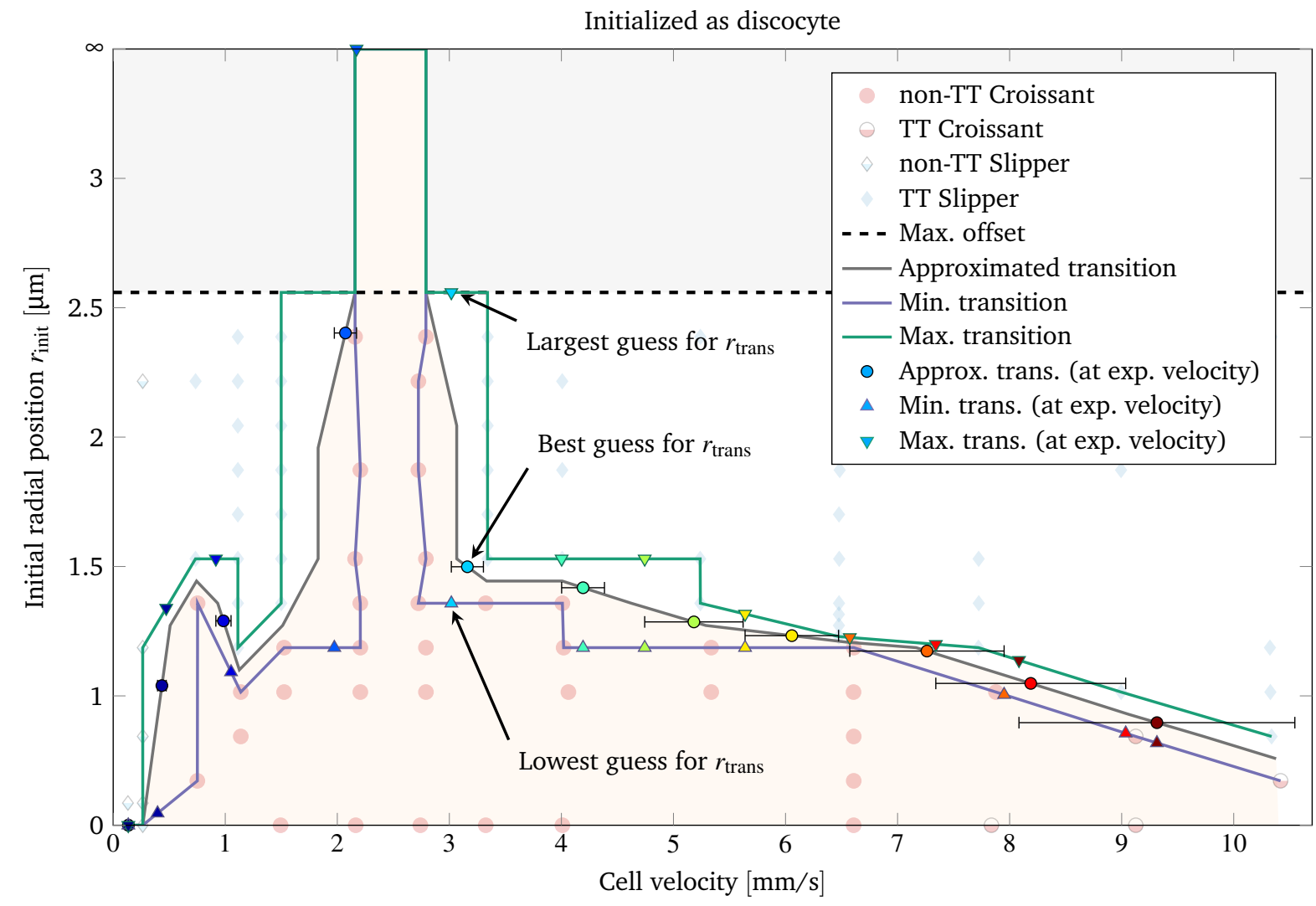

Figure S5: Numerical phase diagram from figure 6(a) from the main text for the discocyte starting shape. The nearly transparent shape symbols and the maximal offset are identical to figure 6(a). The violet, gray and green lines depict the minimal, average and maximal position, respectively, of the transition threshold $r_{\text {trans }}$ between croissants and slippers. These lines are evaluated at the experimental velocities $u$ and $u \pm \sigma_{u}$, giving the circular and triangular symbols. Each triple of these symbols that shares the same color corresponds to one particular experimental velocity and shows the lowest, best and largest guess for $r_{\text {trans }}$. This is exemplified via the three labels and arrows for $u \pm \sigma_{u}=(3.16 \pm 0.14) \mathrm{mm} / \mathrm{s}$ which corresponds to a pressure drop of $\Delta P=300 \mathrm{mbar}$. The horizontal error bars depict $\sigma_{u}$. Also note that in the croissant-only region we take $r_{\text {trans }} \rightarrow \infty$, as indicated by the $\infty$ symbol on the top left. 
Fourth, we search for the minimum $\left(\phi_{\min }\right)$ and maximum $\left(\phi_{\max }\right)$ of these 27 values. $\phi_{\min }$ and $\phi_{\max }$ are then interpreted as the uncertainty in the prediction. The vertical error bars in figure 8 from the main text therefore depict $\phi_{\min }$ and $\phi_{\max }$.

All of this is performed not only for the phase diagram with the discocyte, but also for the ones with the croissant and slipper starting shapes. In case of the croissant starting shape, $r_{\text {trans }}$ is not a proper function due to the protrusions, i.e. we find several transition offsets for certain velocities (compare figure 6 in the main text). Hence, the simple "counting of cells that enter with an offset below $r_{\text {trans }}$ " to form the prediction becomes a "counting of cells that enter with offsets in the intervals formed by the numerical transition offsets". As an example, if a certain velocity leads to transitions at $r_{1}, r_{2}$ and $r_{3}$ (such that the simulations yield croissants in the two intervals $\left[0, r_{1}\right]$ and $\left[r_{2}, r_{3}\right]$ ), then we count how many cells enter the channel with an offset that lies in these two intervals (after their projection on the $y$-axis). The computation of the uncertainty is adapted accordingly.

\section{S4 Additional experimental data}

We depict in figure $\mathrm{S} 6$ the measured cell velocities for each applied pressure drop $\Delta P$. The data shows the result when the averaging goes over all cells regardless of their shape ("All"), and also for the three shape classes separately. Obviously, the cell velocities are roughly proportional to $\Delta P$. However, croissants tend to be a bit faster than slippers because croissants are located in the high-velocity center of the channel while slippers are off-centered (see the main text). This is in agreement with previous publications $[1,2]$.

Table S1 lists the corresponding raw data, as well as the number of cells that were taken into account. It additionally shows the number of cells at the channel entrance. The raw images from the experiments are included in sections S6 and S7 below.

Furthermore, we list in an extra Excel sheet (SI_rawYPos_pos0.xls) the raw $y$-positions of the cells at the channel entrance. This data makes it possible to compare one's own simulation results with our experiments (as we did in figure 8 in the main text).

Moreover, figure S7 depicts the experimental $y$-offset distributions separated into the contributions from the three different shapes (croissants, slippers and "others") at position $x=10 \mathrm{~mm}$ in the channel. This figure complements figure 3(b) from the main text where all three shapes have been considered together.

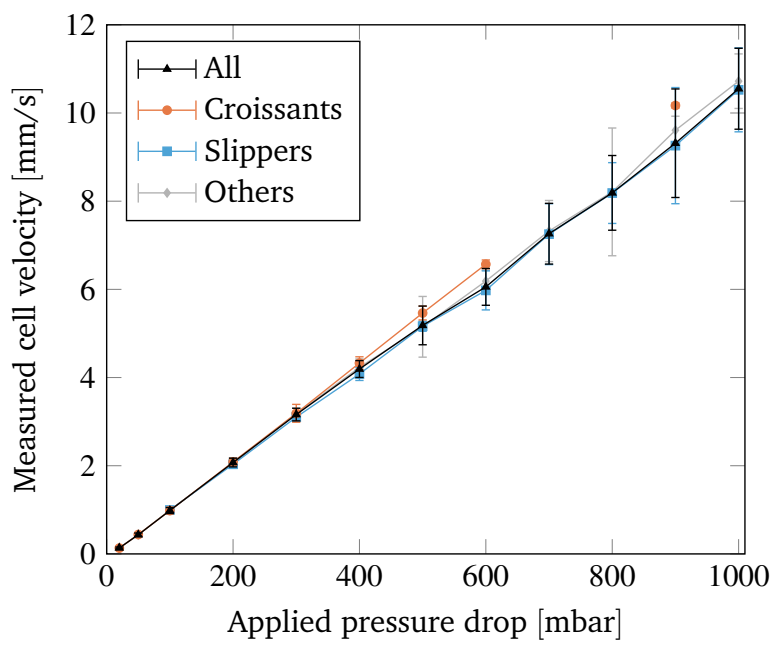

Figure S6: Measured average cell velocities for each applied pressure drop for the three different shape classes and once for all shapes together ("All"). The vertical error bars depict the standard deviation $\sigma_{u}$. Measurements performed at position $x=10 \mathrm{~mm}$ in the channel. The corresponding raw data is listed in table $\mathrm{S} 1$. The lines are guides for the eyes.

\section{S5 References}

[1] S. Quint, A. F. Christ, A. Guckenberger, S. Himbert, L. Kaestner, S. Gekle, and C. Wagner, "3D tomography of cells in micro-channels," Appl. Phys. Lett. 111, 103701 (2017).

[2] G. Tomaiuolo, M. Simeone, V. Martinelli, B. Rotoli, and S. Guido, "Red blood cell deformation in microconfined flow," Soft Matter 5, 3736 (2009). 


\begin{tabular}{lccccccccc}
\hline$\Delta P[\mathrm{mbar}]$ & $N_{0}^{\text {all }}$ & $N_{10}^{\text {all }}$ & $N_{10}^{\text {Crois }}$ & $N_{10}^{\text {Slipper }}$ & $N_{10}^{\text {Other }}$ & $u_{10}^{\text {all }}[\mathrm{mm} / \mathrm{s}]$ & $u_{10}^{\text {Crois }}[\mathrm{mm} / \mathrm{s}]$ & $u_{10}^{\text {Slipper }}[\mathrm{mm} / \mathrm{s}]$ & $u_{10}^{\text {Other }}[\mathrm{mm} / \mathrm{s}]$ \\
\hline 20 & 35 & 107 & 9 & 0 & 98 & $0.135 \pm 0.021$ & $0.132 \pm 0.020$ & & $0.135 \pm 0.021$ \\
50 & 10 & 52 & 9 & 0 & 43 & $0.43 \pm 0.04$ & $0.440 \pm 0.005$ & & $0.43 \pm 0.04$ \\
100 & 29 & 205 & 165 & 2 & 38 & $0.98 \pm 0.07$ & $0.98 \pm 0.07$ & $0.996 \pm 0.002$ & $0.99 \pm 0.04$ \\
200 & 71 & 484 & 252 & 22 & 210 & $2.07 \pm 0.10$ & $2.09 \pm 0.08$ & $2.03 \pm 0.06$ & $2.06 \pm 0.12$ \\
300 & 95 & 475 & 102 & 120 & 253 & $3.16 \pm 0.14$ & $3.19 \pm 0.20$ & $3.10 \pm 0.09$ & $3.18 \pm 0.13$ \\
400 & 90 & 463 & 80 & 167 & 216 & $4.19 \pm 0.19$ & $4.33 \pm 0.14$ & $4.08 \pm 0.15$ & $4.23 \pm 0.19$ \\
500 & 179 & 215 & 17 & 117 & 81 & $5.2 \pm 0.4$ & $5.46 \pm 0.16$ & $5.16 \pm 0.11$ & $5.2 \pm 0.7$ \\
600 & 151 & 176 & 8 & 124 & 44 & $6.1 \pm 0.4$ & $6.57 \pm 0.10$ & $6.0 \pm 0.4$ & $6.19 \pm 0.25$ \\
700 & 159 & 123 & 0 & 105 & 18 & $7.3 \pm 0.7$ & & $7.3 \pm 0.7$ & $7.3 \pm 0.7$ \\
800 & 75 & 200 & 0 & 169 & 31 & $8.2 \pm 0.8$ & & $8.2 \pm 0.7$ & $8.21 \pm 1.40$ \\
900 & 187 & 282 & 2 & 241 & 39 & $9.3 \pm 1.2$ & $10.17 \pm 0.06$ & $9.3 \pm 1.3$ & $9.6 \pm 0.3$ \\
1000 & 141 & 305 & 0 & 266 & 39 & $10.6 \pm 0.9$ & & $10.5 \pm 1.0$ & $10.7 \pm 0.6$ \\
\hline
\end{tabular}

Table S1: Experimental data: The table lists for each applied pressure drop $\Delta P$ the total number of analyzed cells $N_{0}^{\text {all }}$ at position $x=0 \mathrm{~mm}$ in the channel and the total number of analyzed cells $N_{10}^{\text {all }}$ at position $x=10 \mathrm{~mm}$. For the latter we also show the number of croissants, slippers and "others", together with the measured velocities $u_{10}$. The uncertainties are the standard deviation. The subscripts " 0 " and "10" in the heading specify the $x$-position in the channel $(0 \mathrm{~mm}$ or $10 \mathrm{~mm})$.

(a) Croissants

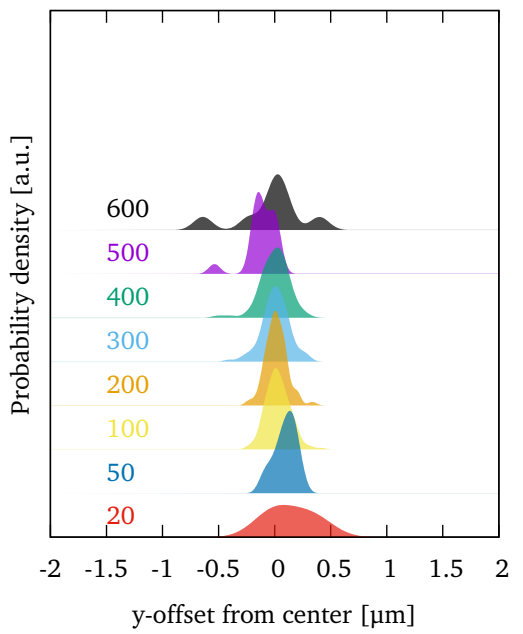

(b) Slippers

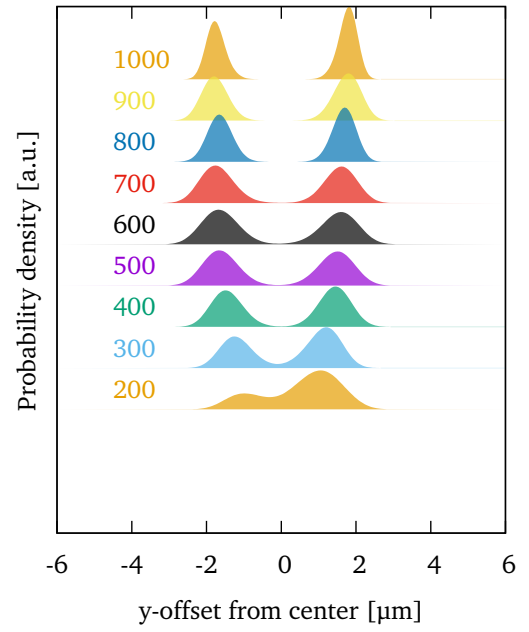

(c) Others

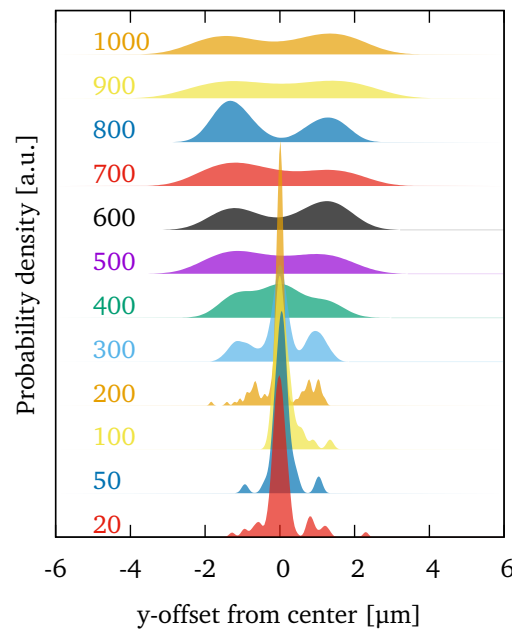

Figure S7: Estimated probability density functions for the experimental $y$-offset distributions at position $x=10 \mathrm{~mm}$ in the channel for (a) the croissant, (b) the slipper and (c) the "other" shapes. The result for all three shapes combined was shown in figure 3(b) in the main text. The area below each curve is normalized to 1, and they are offset in the vertical direction for illustration purposes. Also note the different scale of the horizontal axis in the first figure. 


\section{S6 Raw experimental images at $x=10 \mathrm{~mm}$}

Note: The images in the individual collections are ordered from centered to off-centered.

Note: Many of the "others" (e.g. for $\Delta P=200$ mbar) might be croissants, but they can also be slippers that are viewed from the "top" (i.e. when camera would point along the $z$-direction, one might see slippers). Since we cannot decide this from these images, we classify them as "others".

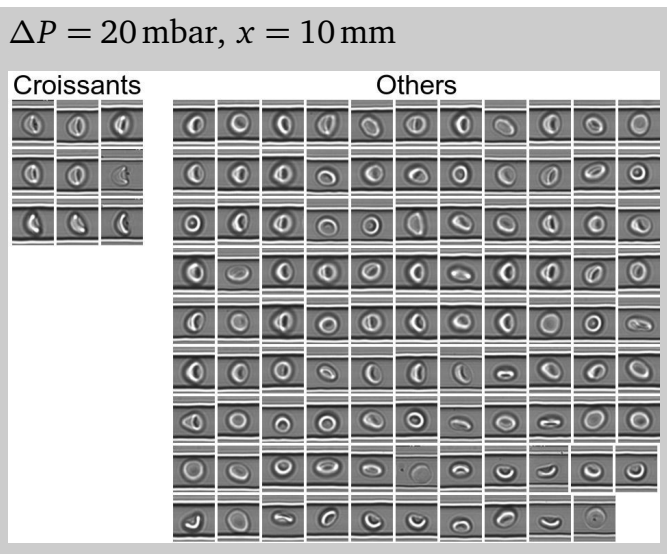

\begin{tabular}{|c|c|c|c|c|c|c|c|c|c|c|}
\hline$\Delta P$ & & 50 & & & & & & & & \\
\hline Cro & ssa & & & & & Oth & & & & \\
\hline 0 & & ( & (a) & (1) & (1) & 0 & ( & (1) & (1) & (1) \\
\hline Q & (8) & (a) & 0 & 0 & (0) & $\sqrt{1}$ & (1) & (8) & (1) & (1) \\
\hline a & (1) & (1) & a & (1) & (1) & (1) & & a & (1) & ( \\
\hline & & & (1) & (c) & (1) & (1) & (1) & (8) & (1) & (1) \\
\hline & & & (1) & (1) & (1) & (1) & C & e & $a$ & $\theta$ \\
\hline & & & & $\theta$ & 0 & & & & & \\
\hline
\end{tabular}

\begin{tabular}{|c|c|c|c|c|c|c|c|c|c|c|c|c|c|c|c|c|c|c|c|}
\hline \multicolumn{20}{|c|}{$\Delta P=100 \mathrm{mbar}, x=10 \mathrm{~mm}$} \\
\hline \multicolumn{13}{|c|}{ Croissants } & \multirow{2}{*}{ 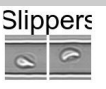 } & \multicolumn{6}{|c|}{ Others } \\
\hline (1) & (1) & (6) & Q & (6) & (a) & 8 & Q) & 8 & 9 & (1) & 80 & a & & ब & a & (a) & (a) & 0 & (a) \\
\hline (6) & ब & (ब) & (1) & (a) & a 5 & Q & Q & ब & (1) & (a) & a 8 & (1) & & (0) & a & (ब) & (1) 1 & (1) & 近 \\
\hline (a) & Q & (a) & (1) & (c) & Q & Q & Q & Q & Q & a & 98 & (1) & & (2) & a & ब & (1) 8 & 1 & a \\
\hline (1) & (9) & (1) & (1) & (1) & Q & Q & Q) & 8 & (9) & ब & 80 & 1 & & & (1) & (1) & $(18$ & (1) & (2) \\
\hline (a) & (1) & (ब) & (a) & (1) & Q & (8) & (a) & 8 & (e) & a & (a) & (1) & & (1) & (0) & @ & Q 01 & (1) & 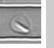 \\
\hline (6) & (1) & 9 & (a) & (1) & a & 0 & a & (ब) & Q & e & a 0 & (6) & & (8) & 0 & a & & & \\
\hline c & 9 & ब & 8 & 8 & ब & 0 & (1) & I & 1 & (a) & 00 & ब & & & & & & & \\
\hline 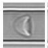 & (a) & (a) & (1) & (a) & (a) & Q & a & ब & (1) & a & (1) & a & & & & & & & \\
\hline 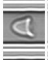 & (1) & (1) & Q & Q & Q & Q & Q & Q & (8) & Q & (a) & 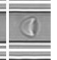 & & & & & & & \\
\hline (ब) & (1) & a & (a) & Q & 9 & 0 & a & (1) & (ब) & 0 & (1) & Q & & & & & & & \\
\hline (बa & (6) & (8) & (a) & 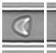 & 9 & Q & ब & 0 & a & ( ब & (ब) & a & & & & & & & \\
\hline Q & (1) & a & 0 & 8 & a & ( & (1) & Q1 & (1) & Q & & & & & & & & & \\
\hline
\end{tabular}




\begin{tabular}{|c|c|c|c|c|c|c|c|c|c|c|c|c|c|c|c|c|c|c|c|c|c|c|c|c|c|c|c|}
\hline \multicolumn{11}{|c|}{ Croissants } & \multicolumn{4}{|c|}{ Slippers } & \multicolumn{12}{|c|}{ Others } & \\
\hline (a) & 0 & \begin{tabular}{l|l}
8 & 0 \\
\end{tabular} & \begin{tabular}{|l|l}
8 & 8 \\
\end{tabular} & 00 & द & a & (a) 0 & 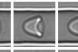 & Q 8 \& 8 & (3) & $\begin{array}{ll}\theta \\
\end{array}$ & ब & & Dब & $\begin{array}{ll}1 & 8 \\
\end{array}$ & (a) & a $=$ & & ब( & (c) & (1) (1) & a & & (1) 8 & a & ब & \\
\hline बs & ब & ब 9 & \begin{tabular}{l|l}
8 & 0 \\
\end{tabular} & (a) 8 & (a & a & 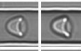 & $20 \mathrm{~s}$ & 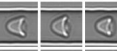 & (3) & \begin{tabular}{l|l}
8 & 0 \\
\end{tabular} & $\theta$ & $\theta 0$ & 80 & (1) \& & 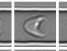 & a & & (ब) & (c) & (c) 1 & बe & (ब) & \begin{tabular}{l|l|} 
& $\mathbb{C}$ \\
\end{tabular} & $\mathbb{a}$ & (1) & \\
\hline & a & (6) & \begin{tabular}{l|l}
0 & 0 \\
\end{tabular} & $8<$ & ब & a & Q & a & Q 80 & (9) & \begin{tabular}{l|l}
$\theta$ & 0 \\
\end{tabular} & ब & 00 & & (ब) ब & बa & a & & (e) & (a) & (1) 1 & (c) & & (1) (6) & 石 & (ब) & \\
\hline Q 6 & 0 & 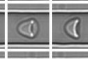 & (a) & \& 6 & 还 & Q & ब 8 & ब & 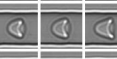 & (3) & 0 & a & $\theta$ & & Q 18 & ब & (1) & (c) & (a) & (1) & (4) & ब & 石 & $\begin{array}{lll} & & \\
\end{array}$ & a & 石 & \\
\hline $\begin{array}{ll}a \\
\end{array}$ & e & $ه 8$ & (ब) 6 & 80 & e & Q & \begin{tabular}{l|l}
0 & 0 \\
\end{tabular} & $0<$ & $8 \& 8$ & & & & & & 80 & ब & (6) & ब & बa & Q & (c) 8 & ब & Q & a & ब & 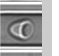 & \\
\hline 9 & a & a 0 & \begin{tabular}{|l|l}
0 & $\mathbb{8}$ \\
\end{tabular} & 00 & (a) & e & $9 \sqrt{8}$ & Q & \& 80 & & & & & & \begin{tabular}{l|l} 
\\
\end{tabular} & ब & e & (1) & a & (a) & (1) ब & ब & (9) & \begin{tabular}{l|l|}
$a$ & 0 \\
\end{tabular} & ब & 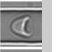 & \\
\hline Q 6 & (6) & 00 & Q 0 & 00 & Q & a & $\begin{array}{lll}0 & 0 \\
\end{array}$ & \& & \begin{tabular}{l|l|l} 
& 8 & 8 \\
\end{tabular} & & & & & & $\begin{array}{ll} & 0 \\
\end{array}$ & ब & ब & a & e & 8 & 1 (1) & Q & (ब1 & (1) & 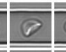 & 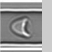 & \\
\hline Q 18 & 0 & 00 & \begin{tabular}{l|l}
0 & 0 \\
\end{tabular} & 86 & a & (c) & \begin{tabular}{l|l}
0 & 0 \\
\end{tabular} & a & (1) $\quad 0 \quad 8$ & & & & & & (ब 8 & a & a & (1) & (ब) & Q) & (1) & (1) & $\overline{10}$ & $a \sqrt{8}$ & 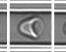 & (ब) & \\
\hline बe & Q & ब 8 & \begin{tabular}{ll|l}
6 & 0 \\
\end{tabular} & \& 8 & (9) & e & \begin{tabular}{l|l}
$6 \rho$ \\
\end{tabular} & ब & (4) 8 & & & & & & \& a & ब & ब1 & (c) & 遇 & ब & (8) 8 & 要 & (1) & \begin{tabular}{l|l|} 
& $\mathbb{6}$ \\
\end{tabular} & ब & (1) & \\
\hline \begin{tabular}{l|l}
0 & 0 \\
\end{tabular} & e & a 6 & $\begin{array}{lll}8 & 0 \\
\end{array}$ & $0<$ & 退 & a & ब 8 & $0<$ & $\begin{array}{llllllllllll} & 0 & 0 \\
\end{array}$ & & & & & & (1) & ब & 8 & (ब) & (c) & a & 8 & ब & e & 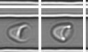 & e & (1) & \\
\hline 0 & 8 & 00 & (a) & 80 & 退 & (a) & \begin{tabular}{l|l} 
& 0 \\
\end{tabular} & Q & 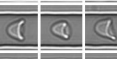 & & & & & & 0 & 0 & 0 & 0 & ब, & ब & (6) & (1) & $\overline{\bar{a}}$ & 00 & $\overline{\overline{0}}$ & 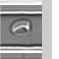 & \\
\hline 0 这 & 8 & \begin{tabular}{|l|l}
0 & 0 \\
\end{tabular} & \begin{tabular}{l|l|}
8 & 0 \\
\end{tabular} & Q 6 & e & Q & \begin{tabular}{l|l}
0 & 8 \\
\end{tabular} & $0 \mathrm{C}$ & 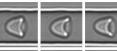 & & & & & & $\begin{array}{ll}\theta & \theta \\
\end{array}$ & (a) & e & (9) & ef & 8 & e & Q & $\overline{0}$ & 0 & 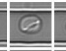 & 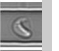 & \\
\hline & 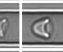 & 80 & Q 0 & 80 & e & a & 0 & Qs & $0 \quad 0 \quad 0$ & & & & & & 80 & e & 0 & & e & ef & Oे & O & & e e & & 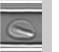 & \\
\hline 0 & e & $\begin{array}{lll}0 & 6 \\
\end{array}$ & (ब) & ब ब & (9) & Q & 80 & Q & Q 60 & & & & & & 00 & $\theta$ & $\theta$ & 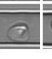 & of & o. & 8 & $\theta$ & 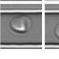 & 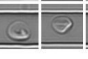 & क & (ब) & \\
\hline Q 9 & 8 & 08 & \begin{tabular}{|l|l|} 
& 0 \\
\end{tabular} & Q 9 & & Q & Q6 & Q & & & & & & & & & & & & & & & & & & & \\
\hline \multicolumn{28}{|c|}{$\Delta P=300 \mathrm{mbar}, x=10 \mathrm{~mm}$} \\
\hline \multicolumn{7}{|c|}{ Croissants } & \multicolumn{8}{|c|}{ Slippers } & \multicolumn{13}{|c|}{ Others } \\
\hline & a & \begin{tabular}{l|l}
9 & 8 \\
\end{tabular} & \begin{tabular}{|l|l|} 
& 0 \\
\end{tabular} & Q 10 & 8 & e & @ & $\Phi$ & 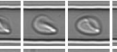 & & (क) & & a & & 0.0 & (1) & (c) & (1) & ब & (a) & $\begin{array}{lll}1 & 1 \\
\end{array}$ & (4) & a & $0 / 0$ & (1) & & \\
\hline 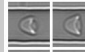 & 0 & \begin{tabular}{l|l}
6 \\
\end{tabular} & \begin{tabular}{|l|l|} 
& 0 \\
\end{tabular} & 80 & 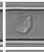 & a & Q & (a & 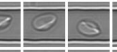 & e & Q & a & 9 & & ब & es & 0 & (1) & (0) & () & (1) 8 & ब & e & \begin{tabular}{l|l}
19 \\
\end{tabular} & ब & e & \\
\hline 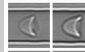 & 8 & \begin{tabular}{|l|l|}
$a$ & 0 \\
\end{tabular} & 48 & (4) & ब & (a) & es & ê & $\Delta 0$ & 0 & e & 包 & $\theta$ & 0 & (1) 6 & ब & \& & (1) & (a) & (1) & (a) & ब & (a) & 10 & ब & 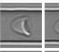 & 9 \\
\hline & 8 & \begin{tabular}{|l|l|}
8 & 0 \\
\end{tabular} & \begin{tabular}{|l|l|}
0 & 0 \\
\end{tabular} & \begin{tabular}{ll|}
8 & 0 \\
\end{tabular} & a & 0 & (1) & 00 & 300 & 8 & ब同 & ब & 8 & & ब & ब & ब & ब & 0 & (1) & (4) 1 & of & (1) & \begin{tabular}{l|l|}
1 & $\mathbb{1}$ \\
\end{tabular} & ब & 0 & \\
\hline 9 & 8 & \begin{tabular}{|l|l|}
9 & 8 \\
\end{tabular} & \begin{tabular}{|l|l|}
0 & 0 \\
\end{tabular} & \begin{tabular}{|l|l|}
0 & 8 \\
\end{tabular} & 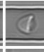 & 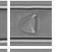 & $\overline{10}$ & $\underline{\theta \theta}$ & 500 & ब更 & 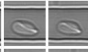 & 3 & $Q$ & 9 & 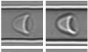 & e & e & (1) & (8) & 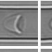 & (2) & ब & (1) & \begin{tabular}{l|l|l} 
Q & 0 \\
\end{tabular} & 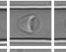 & (1) & (1) \\
\hline 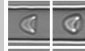 & ब & \begin{tabular}{l|l}
8 & 0 \\
\end{tabular} & \begin{tabular}{|l|l|}
8 & 0 \\
\end{tabular} & $8 \&$ & Q & e & 垔 & 80 & $\theta \theta$ & 앙 & ब & 0 & & 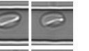 & (19) 1 & a & (8) & (1) & 过 & 3 & $\begin{array}{lll}8 & 1 \\
\end{array}$ & ब & (1) & 00 & Q & 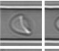 & \begin{tabular}{l|l}
8 & 8 \\
\end{tabular} \\
\hline $\begin{array}{lll}0 & 0 \\
\end{array}$ & 0 & 80 & \begin{tabular}{|l|l|}
9 & 0 \\
\end{tabular} & 80 & $\bar{a}$ & e & 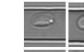 & 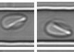 & 00 & (a) & $\theta 0$ & ब & 0 & $\overline{6}$ & \begin{tabular}{l|l}
1 & $\mathbb{C}$ \\
\end{tabular} & ब & a & (a) & c) & (1) & 10 & 8 & as & 80 & o & $\mathbb{a}$ & $\bar{e}$ \\
\hline & ब & \begin{tabular}{l|l}
0 & 0 \\
\end{tabular} & \begin{tabular}{l|l}
0 & 8 \\
1
\end{tabular} & 19 & 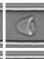 & (a) & 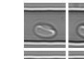 & (을 & 00 & 욜 & e & 0 & 알 & 1 & (1) & ब & a & (a) & (p) & a & 10 & ब्व & 可 & e区 & a & 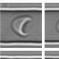 & a. \\
\hline 88 & & \begin{tabular}{l|l}
8 & 0 \\
\end{tabular} & \begin{tabular}{l|l}
0 & 0 \\
\end{tabular} & 8 ब & (a) & 3 & 0 & 0 & 00 & 0 & 0 & & & & 83 & (a) & (2) & 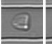 & a & ब & (2) & e & 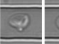 & 80 & 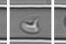 & 0 & e \\
\hline 98 & (8) & & & & & & $\begin{array}{ll}0 \\
\end{array}$ & a高 & 00 & ह & & $\theta$ & & 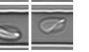 & $\begin{array}{ll}0 & 0 \\
\end{array}$ & 表 & e & $\Theta$ & e & $\overline{0}$ & 0 & 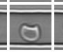 & (2) & Q & 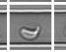 & Q & 8 \\
\hline & & & & & & & & & & & & & & & 0 & 10 & & (e) & 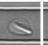 & I & & & & (1) $=$ & a & 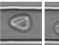 & 0 \\
\hline & & & & & & & & & & & & & & & (c) & es & 0 & & ef & & 0 & o & & \begin{tabular}{l|l|}
2 & 3 \\
\end{tabular} & e) & 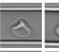 & \\
\hline & & & & & & & & & & & & & & & e & es & & ब & 拿 & $\theta$ & 8 & ब & & \begin{tabular}{|l|l|}
8 & 3 \\
\end{tabular} & 3 & 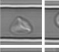 & \\
\hline & & & & & & & & & & & & & & & 0 & 0 & & 2 & & & 0 & e & & 00 & ब & e & \\
\hline & & & & & & & & & & & & & & & & 3 & & & & & $\Rightarrow$ & & & & & 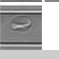 & \\
\hline
\end{tabular}




\section{$\Delta P=400$ mbar, $x=10 \mathrm{~mm}$}

\begin{tabular}{|c|c|c|c|c|c|c|c|c|c|c|c|c|c|c|c|c|c|c|c|c|c|c|c|c|c|c|c|c|c|c|c|c|c|c|c|}
\hline \multicolumn{10}{|c|}{ Croissants } & \multicolumn{11}{|c|}{ Slippers } & \multicolumn{15}{|c|}{ Others } \\
\hline C) & (6) & (1) & \& & \& & 8 & \& & 8 & 8 & 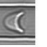 & 0 & Q10 & 00 & 0 & o & $\therefore 0$ & 0 & $\Delta$ & \begin{tabular}{l|l}
0 & $c$ \\
\end{tabular} & $\$ 0$ & $e$ & 0 & Q & (1) & c & (1) & त) & $\begin{array}{lll}1 & 8 \\
\end{array}$ & a & (1) & (1) & ब1 & $\mathbb{8}$ & ब & (1) & (1) \\
\hline a & 8 & Q & e & (6) & a & e & ब & Q & (4) & Q & $Q \bar{C}$ & a & ब & 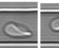 & 0 & ब & 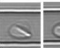 & e & 8 & 0 & (1) & ब & a) & (1) & as & o & 00 & Q & (1) & ब & (1) & ब & (1) & (1) & (1) \\
\hline 8 & 8 & 8 & 8 & (a) & 8 & Q & e & a & 8 & Q & as & Q & 0 & ब & 50 & $\theta$ & ec & ac & 8 & $\theta$ & ब & (a) & Q & Q & c & (1) & (3) & (1) & (1) & ब & a & बa & (3) & ब1 & Q \\
\hline 8 & 0 & (c) & ब & 8 & (1) & ब & 8 & 8 & a & ब & $\Delta \bar{c}$ & 0 & Q & $\bar{c}$ & 60 & $\sigma$ & sc & $0 \mathrm{c}$ & 30 & 0 & a & ब & Q & Q & Q1 & (3) & 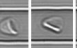 & (c) & ब1 & 6 & 8 & Q & ब1 & $\bar{E}$ & (c) \\
\hline 8 & Q & (1) & a & 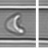 & 8 & 4 & a & 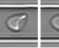 & $\theta$ & Q & Q $\bar{c}$ & as & $\bar{a}$ & $\theta \quad$ & 80 & $\theta$ & 0 & oc & 3 & $\theta$ & e & 0 & c|c & ब & 8 & 8 & 8 & $\otimes$ & ब & 0 & 0 & (]) & 0 & 3 & 8 \\
\hline & & & & & & & & & & ब & 0 & $0 \Omega$ & 8 & 96 & 50 & 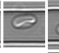 & 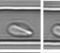 & $\theta \varepsilon$ & 30 & $\infty$ & $\theta$ & es & (2) & 9 & ह & 0 & 58 & 9 & 8 & 0 & 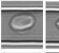 & 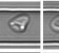 & 0 & 9 & Q \\
\hline & & & & & & & & & & Q & 0 & eह & 0 & 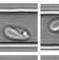 & 80 & $\sigma$ & 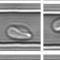 & 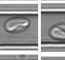 & 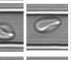 & 0 & 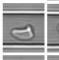 & 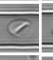 & 8 & Q $\overline{\bar{c}}$ & ब & $\underline{\underline{\theta}}$ & \begin{tabular}{l|l|} 
& 8 \\
\end{tabular} & (6) & (a) & ब & ब & $\otimes$ & ब & 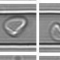 & Q \\
\hline & & & & & & & & & & 0 & 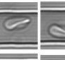 & 00 & ब & 92 & 80 & 0 & 0 & 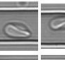 & 8 & $\sigma$ & 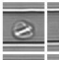 & $\overline{8}$ & $\theta$ & (2) & ब) & 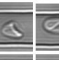 & 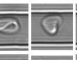 & 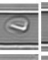 & 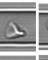 & 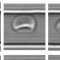 & 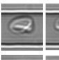 & 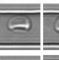 & (3) & 0 & 할 \\
\hline
\end{tabular}

\section{$\Delta P=500$ mbar, $x=10 \mathrm{~mm}$}

\begin{tabular}{|c|c|c|c|c|c|c|c|c|c|c|c|c|c|c|c|c|c|c|c|c|c|c|c|c|c|}
\hline \multicolumn{5}{|c|}{ Croissants } & \multicolumn{12}{|c|}{ Slippers } & \multicolumn{9}{|c|}{ Others } \\
\hline 8 & 8 & $\mathbb{8}$ & 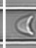 & (6) & Q & 0 & 0 & $\theta$ & e & Q & Q & $\theta$ & $\theta$ & $\theta$ & 0 & $\theta$ & ब & (6) & (1) & (1) & 0 & (1) & (1) & Q & 8 \\
\hline C & 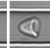 & 8 & ब & a & 0 & $\theta$ & $\odot$ & Q & 0 & Q & 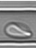 & $\infty$ & (1) & 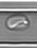 & 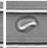 & $\theta$ & 0 & (1) & (1) & Q & 0 & C & $ब$ & 8 & $\theta$ \\
\hline (1) & 8 & (8) & (c) & $\mathbb{8}$ & e & 0 & $\theta$ & $\sigma$ & 0 & 0 & Q & 0 & $\theta$ & 9 & $\theta$ & 0 & (9) & $\ominus$ & $\infty$ & Q & $\theta$ & $\theta$ & $\Theta$ & Q & 0 \\
\hline 8 & ब & & & & 0 & $\theta$ & o & Q & 0 & c & (2) & 0 & ब & $\theta$ & 0 & 0 & (c) & ब & 0 & 0 & 0 & e & 8 & 8 & Q \\
\hline & & & & & $\theta$ & $\theta$ & $\Theta$ & 0 & 0 & es & 0 & $\varnothing$ & (ब) & $\theta$ & $\theta$ & 0 & $\theta$ & $\overline{\bar{\theta}}$ & $\theta$ & Q & 0 & (8) & $\theta$ & 8 & 8 \\
\hline & & & & & 0 & 0 & 0 & 0 & Q & $\varnothing$ & 0 & $\infty$ & Q & 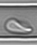 & $\theta$ & $\varnothing$ & (3) & 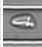 & (4) & (2) & (8) & (2) & Q & $\Leftrightarrow$ & $\theta$ \\
\hline & & & & & 0 & $\theta$ & $\theta$ & 0 & $\Phi$ & $\therefore$ & 8 & $\sigma$ & 0 & $\bar{\sigma}$ & 0 & 0 & $\theta$ & 8 & a & (2) & $\bar{e}$ & $\theta$ & 0 & $\theta$ & 8 \\
\hline & & & & & 0 & $\sigma$ & 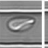 & $\sigma$ & $\theta$ & 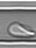 & 0 & $\infty$ & 8 & 0 & 0 & 0 & 0 & ब & $\theta$ & $\theta$ & $\Phi$ & $\theta$ & $\theta$ & (ब) & $\theta$ \\
\hline & & & & & 0 & $\sigma$ & $\infty$ & 0 & 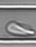 & 0 & 0 & $\sigma$ & 0 & $\sigma$ & $\sigma$ & 0 & 8 & $\theta$ & 0 & $\infty$ & (3) & $\overline{0}$ & 9 & $\theta$ & $\theta$ \\
\hline & & & & & & $\sigma$ & $\infty$ & 0 & $\bar{\theta}$ & $\bar{\sigma}$ & $\infty$ & $\theta$ & $\infty$ & & & & & & & & & & & & \\
\hline
\end{tabular}

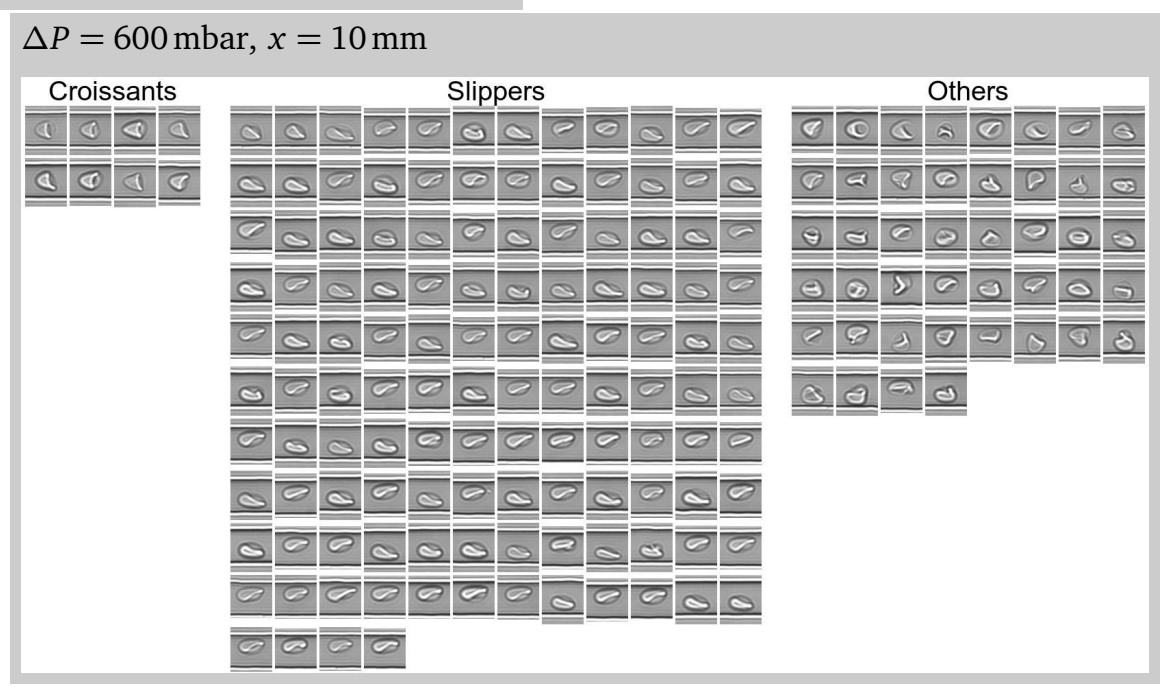


$\Delta P=700$ mbar, $x=10 \mathrm{~mm}$ Slippers

Others

\begin{tabular}{|c|c|c|c|c|c|c|c|c|}
\hline & e & $\sigma \propto$ & 0 & (2) & 0 & 0 & (1) 00 & $\sigma \sqrt{6}$ \\
\hline $\bar{e}$ & a & 0 & 0 & 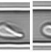 & e & 00 & $\theta \& \theta$ & $0 \overline{0}$ \\
\hline a & Q & es & 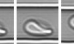 & & $a$ & 00 & $\theta \theta 0$ & 0 \\
\hline o & बह & बक & a & $\Delta c$ & a & 00 & Qब用 & \\
\hline o & $\theta$ & a & 0 & se & $\theta$ & ac & & \\
\hline o & ब & 0 & 0 & $\overline{\bar{s}}$ & e & 00 & & \\
\hline o & $\theta 0$ & $\theta \overline{0}$ & o & $\overline{\bar{c}}$ & 0 & 00 & & \\
\hline 은 & $\theta$ a & ब送 & (2) & & $\theta$ & 00 & & \\
\hline ब & 0 & $\bar{a}$ & 0 & $\overline{6}$ & 0 & ब 0 & & \\
\hline Q & $\theta 6$ & $\bar{a} \bar{e}$ & & & & & & \\
\hline
\end{tabular}

\begin{tabular}{|c|c|c|c|c|c|c|c|c|c|c|c|c|c|c|c|c|c|c|c|}
\hline \multicolumn{20}{|c|}{$\Delta P=800 \mathrm{mbar}, x=10 \mathrm{~mm}$} \\
\hline \multicolumn{13}{|c|}{ Slippers } & \multicolumn{7}{|c|}{ Others } \\
\hline$\sigma$ & $\varnothing$ & $\bar{Q}$ & ब & Q & $\theta$ & e & ब & a & $\theta$ & $\theta$ & e & e & 8 & Q & a & (3) & 0 & 0 & $\theta$ \\
\hline$\theta$ & $\varnothing$ & ब & $\theta$ & $\varnothing$ & $\theta$ & $\theta$ & $\theta$ & $\bar{\theta}$ & $\theta$ & $\Phi$ & a & a & 8 & 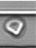 & 8 & 응 & ब & $\theta$ & 8 \\
\hline$\theta$ & $\varnothing$ & Sts & $\theta$ & ब & Q & $\theta$ & $\sigma$ & $\bar{\theta}$ & $\theta$ & e & $\theta$ & $\infty$ & Q & 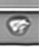 & 8 & 9 & बे & (8) & Q \\
\hline$\sigma$ & a & ब & $\theta$ & a & $\theta$ & 0 & ㅇ & $\theta$ & $\theta$ & $\theta$ & $\theta$ & $\theta$ & $\theta$ & e & 8 & Q & (6) & $\theta$ & $\bar{\theta}$ \\
\hline$\sigma$ & e & 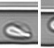 & $\theta$ & $a$ & $\theta$ & $\theta$ & 0 & $\bar{\sigma}$ & $\theta$ & $\varnothing$ & $\varnothing$ & 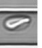 & 3 & 8 & $\sigma$ & & & & \\
\hline$\sigma$ & $\theta$ & $\theta$ & $\bar{a}$ & $\theta$ & $\theta$ & $\sigma$ & 0 & $\bar{\sigma}$ & $\bar{a}$ & 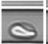 & $\sigma$ & ब & & & & & & & \\
\hline$\theta$ & $\sigma$ & $\bar{Q}$ & $\bar{a}$ & $\theta$ & $\theta$ & $\theta$ & $\theta$ & $\theta$ & $\theta$ & $\theta$ & $\theta$ & 0 & & & & & & & \\
\hline$\sigma$ & 0 & 0 & $\sigma$ & 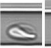 & 0 & $\theta$ & a & $\sigma$ & $a$ & $\theta$ & 을 & e & & & & & & & \\
\hline$\theta$ & 0 & o & a & c & c & $a$ & ब & 요 & 0 & $\theta$ & 0 & c) & & & & & & & \\
\hline$\theta$ & 0 & os & 0 & $\sigma$ & a & Q & a & a & $\theta$ & $\theta$ & 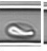 & 0 & & & & & & & \\
\hline$\infty$ & a & a & $\sigma$ & $\theta$ & 0 & $\theta$ & $a$ & $\bar{\theta}$ & $\theta$ & 0 & $\infty$ & $\theta$ & & & & & & & \\
\hline 0 & a & $\sigma$ & 0 & a & $a$ & $\theta$ & $\theta$ & 음 & $\sigma$ & $\theta$ & $\theta$ & $\approx$ & & & & & & & \\
\hline$\infty$ & 0 & $\infty$ & 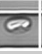 & ब & $\theta$ & 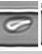 & $a$ & 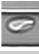 & a & $\theta$ & $\sigma$ & $\sigma$ & & & & & & & \\
\hline
\end{tabular}




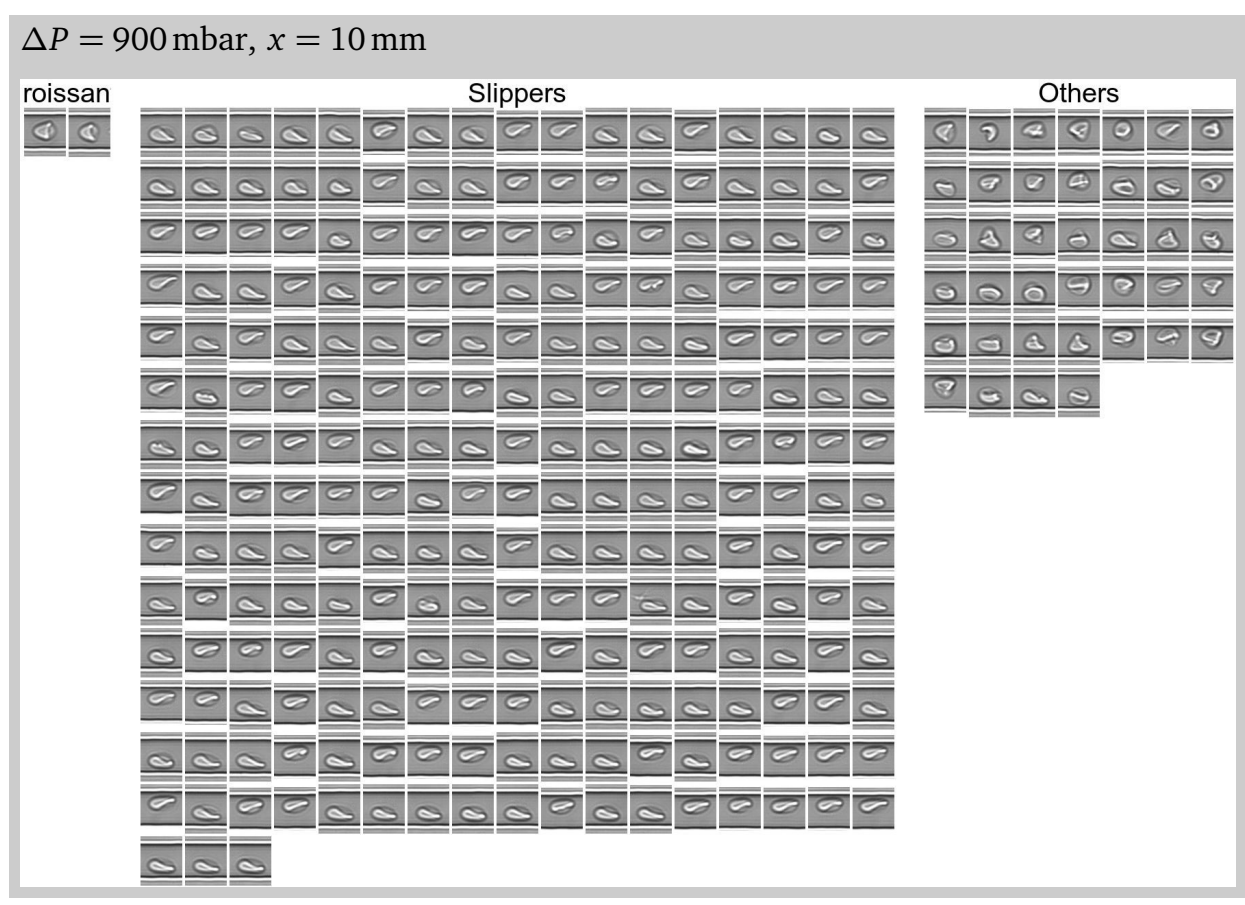

\begin{tabular}{|c|c|c|c|c|c|c|c|c|c|c|c|c|c|c|c|c|c|c|c|c|c|c|}
\hline & $=10$ & & n & ar & $x$ & 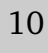 & & & & & & & & & & & & & & & & \\
\hline & & & & & & & $p p \epsilon$ & & & & & & & & & & & & ther & & & \\
\hline$\theta$ & $\odot \odot$ & $\theta$ & 0 & $\theta$ & $\sigma$ & a & $\theta$ & Q & $\theta$ & $\theta$ & Q & $\varnothing$ & a & ब & $\theta$ & $\pi$ & (1) & Q & a & 0 & $\theta$ & D \\
\hline$\odot$ & $0 \sigma$ & 0 & 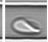 & $\theta$ & a & व & $\theta$ & $\sigma$ & $\sigma$ & 0 & $\theta$ & 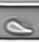 & $\sigma$ & $\theta$ & $\theta$ & $\theta$ & $\theta$ & $\theta$ & 0 & 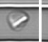 & कह & 8 \\
\hline$\theta$ & $\therefore \sigma$ & $\theta$ & $\theta$ & $\theta$ & $\sigma$ & $\theta$ & $\sigma$ & $\sigma$ & $\varnothing$ & 8 & $\sigma$ & a & $\theta$ & ब & $\theta$ & $\varnothing$ & 9 & a & c & a & 9 & (D) \\
\hline$\theta$ & 00 & a & $\sigma$ & $\theta$ & ब & ब & $\theta$ & ब & $\theta$ & $\sigma$ & e & a & 0 & 0 & $\theta$ & 0 & 8 & 8 & $\Delta$ & 0 & 8 & 은 \\
\hline a & $\therefore 0$ & 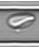 & $\sigma$ & $\theta$ & $\theta$ & a & $\sigma$ & 9 & $\theta$ & $\sigma$ & a & $\bar{\sigma}$ & 0 & $\theta$ & $\theta$ & (ब & 8 & 0 & $\theta$ & 8 & 8 & a \\
\hline e & $\theta \bar{\theta}$ & a & $\sigma$ & $a$ & $\theta$ & $\theta$ & $\sigma$ & 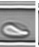 & $\bar{\theta}$ & $\theta$ & 0 & $\sigma$ & a & o & $\theta$ & $\bar{\theta}$ & $\theta$ & 0 & 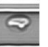 & & & \\
\hline e & $\therefore \sigma$ & $\theta$ & $\theta$ & $\theta$ & $\theta$ & $\sigma$ & $\sigma$ & o & $\theta$ & $a$ & $\bar{\theta}$ & e & $\sigma$ & a & $a$ & & & & & & & \\
\hline$\theta$ & a $a$ & $\theta$ & 0 & $\theta$ & a & a & $\sigma$ & a & a & $\approx$ & e & 0 & o & 0 & o & & & & & & & \\
\hline$\sigma$ & 00 & $\theta$ & $\infty$ & $\theta$ & $\sigma$ & 0 & 0 & a & e & $\sigma$ & $\sigma$ & $\theta$ & $\sigma$ & a & $\theta$ & & & & & & & \\
\hline Q & $\therefore \theta$ & $\sigma$ & 0 & 0 & $\theta$ & 0 & $\sigma$ & $\sigma$ & $\sigma$ & $\sigma$ & a & 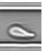 & $\theta$ & $\sigma$ & o & & & & & & & \\
\hline 0 & 00 & $\sigma$ & 0 & 0 & $\theta$ & $\sigma$ & $\theta$ & a & $\sigma$ & $\sigma$ & a & $\sigma$ & $\bar{\sigma}$ & $\theta$ & 0 & & & & & & & \\
\hline$a$ & 00 & $\sigma$ & 0 & 0 & $\sigma$ & a & 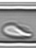 & $\sigma$ & $\theta$ & $\sigma$ & 0 & $\theta$ & a & $\sigma$ & $\infty$ & & & & & & & \\
\hline e & $0 \Omega$ & $a$ & $a$ & $\infty$ & a & $a$ & 0 & 0 & a & $\sigma$ & o & $\theta$ & 0 & 0 & $\theta$ & & & & & & & \\
\hline e & 00 & a & 0 & 0 & $\infty$ & $\sigma$ & 으 & 0 & $\theta$ & $\theta$ & o & $a$ & a & 0 & $\sigma$ & & & & & & & \\
\hline 0 & a & $\theta$ & 0 & 0 & 0 & $\infty$ & $\sigma$ & $\sigma$ & $\theta$ & 0 & 0 & $a$ & $\bar{a}$ & ब & $\sigma$ & & & & & & & \\
\hline a & $\therefore a$ & $a$ & $a$ & $\theta$ & $\theta$ & $\theta$ & $a$ & $\sigma$ & $\sigma$ & $\sigma$ & $\sigma$ & $\infty$ & & & & & & & & & & \\
\hline
\end{tabular}




\section{S7 Raw experimental images at $x=0 \mathrm{~mm}$}

Note: The images in the individual collections are ordered from centered to off-centered.
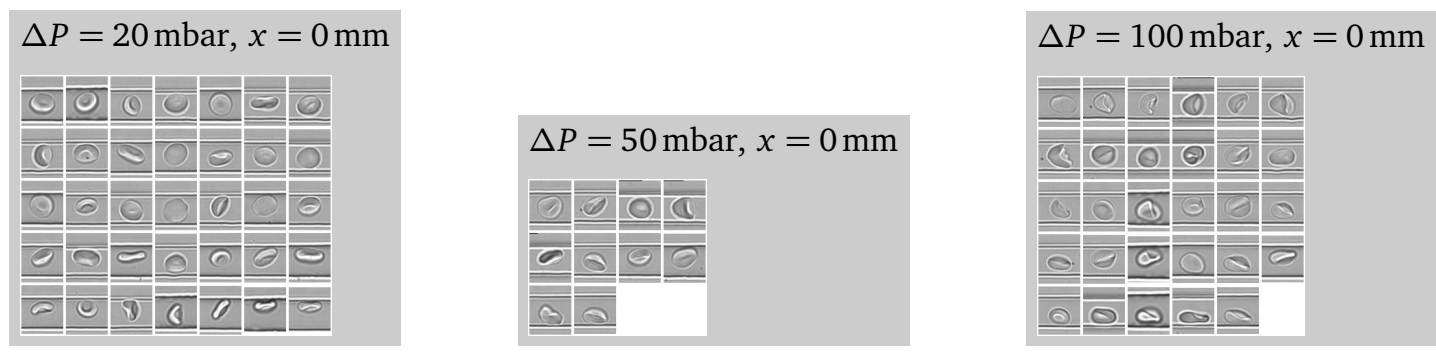

\begin{tabular}{|c|c|c|c|c|c|c|c|c|}
\hline \multicolumn{9}{|c|}{$\Delta P=200 \mathrm{mbar}, x=0 \mathrm{~mm}$} \\
\hline ㅇ. & (2) & 은. & 으. & 0 & (a) & (?) & & (2) \\
\hline 0 & (2) & ( ) & 0 & (8) & 0. & $\mathbb{Q}$ & $\theta$ & 0 \\
\hline$\theta$ & (2) & 0 & (2) & 을 & (8) & (2) & 0 & \\
\hline e & 0 & O & 0 & 0 & 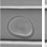 & 0 & 은 & Q \\
\hline (2) & 0 & 0 & 0 & $\theta$ & e & (2) & 으 & $\Theta$ \\
\hline 0 & $\theta$ & (a) & 0 & $\theta$ & 0 & 으 & 0 & $\theta$ \\
\hline 은 & 으 & 0 & $\infty$ & 0 & 0 & 0 & 은 & 0 \\
\hline ㄴ. & 0 & 0 & ه & 0 & 0 & L & 5 & \\
\hline
\end{tabular}
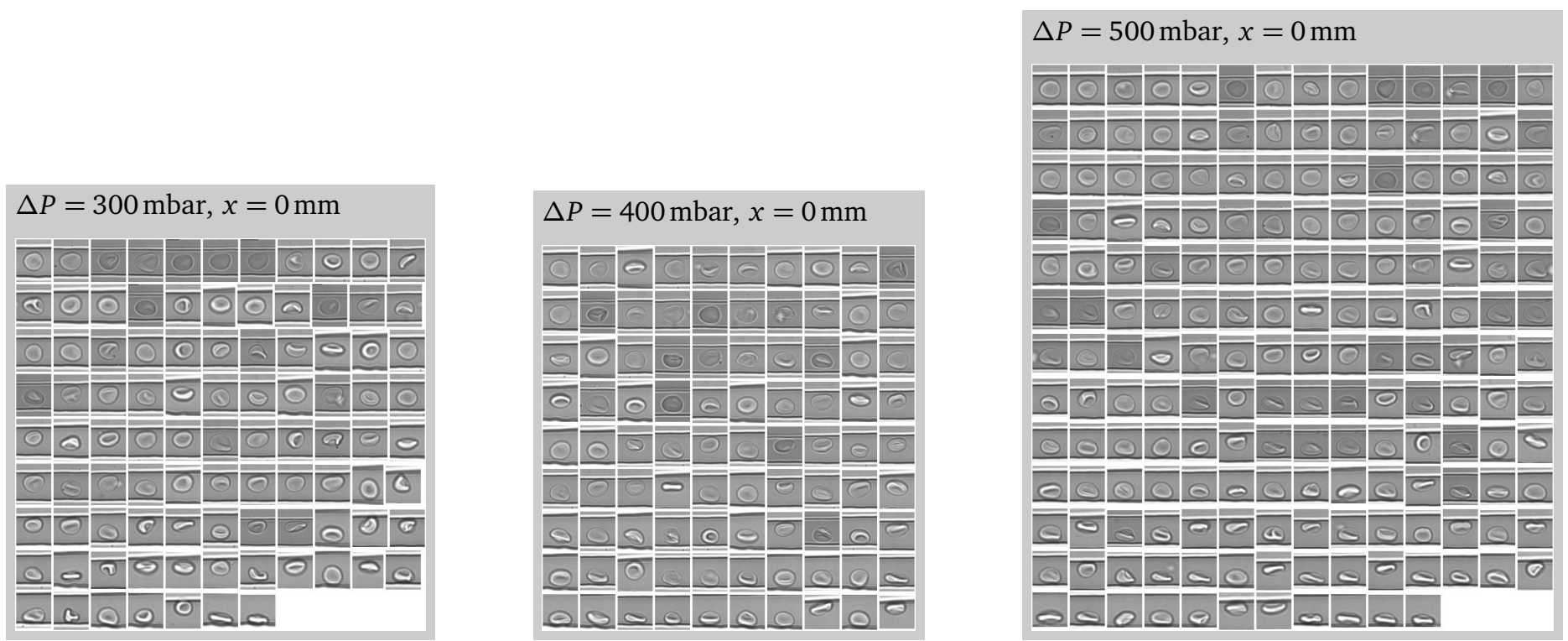


\begin{tabular}{|c|c|c|c|c|c|c|c|c|c|c|}
\hline \multicolumn{11}{|c|}{$\Delta P=600 \mathrm{mbar}, x=0 \mathrm{~mm}$} \\
\hline a & 3 & & C & & 28 & & & & & 0 \\
\hline C & & 0 & & 0 & (b) & 2) & & & & 00 \\
\hline 80 & & & 을 & (8) & & 5. & & & & 을 \\
\hline 으잉 & Q & 0 & 은 & (2) & 5 & & b & & & C \\
\hline$\theta 0$ & Q & 을 & 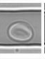 & & s) & & Q) & & 요 & 0 \\
\hline (6) & & 0 & $\overline{0}$ & 음 & (2) & $\frac{5}{2}$ & 5 & 5 & S & 6 \\
\hline$\theta 0$ & & 을 & (2) & & (2) & & & \pm & & ब \\
\hline 0 & 10 & (大) & $\theta$ & 0 & (1) & & & & & \\
\hline $0 \overline{0}$ & $\bar{e}$ & $\theta$ & $\theta$ & 5 & ब) & & & & $\theta$ & $\theta \sigma$ \\
\hline 0 & & 을 & 8 & 을 & & & & & & $\sigma=$ \\
\hline 00 & $\sqrt{e}$ & 인 & $\bar{\sigma}$ & & & e & & & & $\Rightarrow$ \\
\hline 0 & _ & & & & & & & & & \\
\hline
\end{tabular}

$\Delta P=700 \mathrm{mbar}, x=0 \mathrm{~mm}$

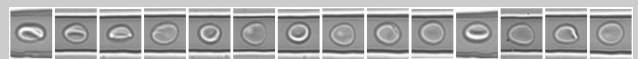

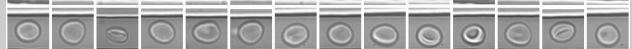

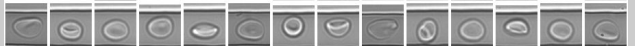

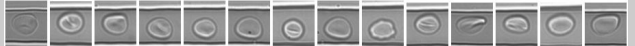

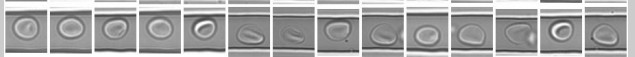

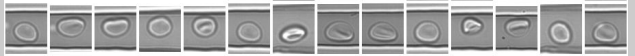

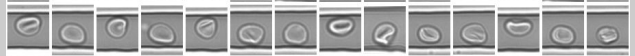

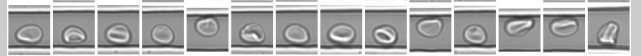

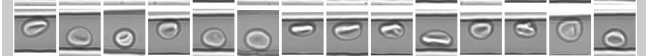
बने बनेंन बन

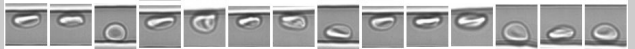
बर ब००

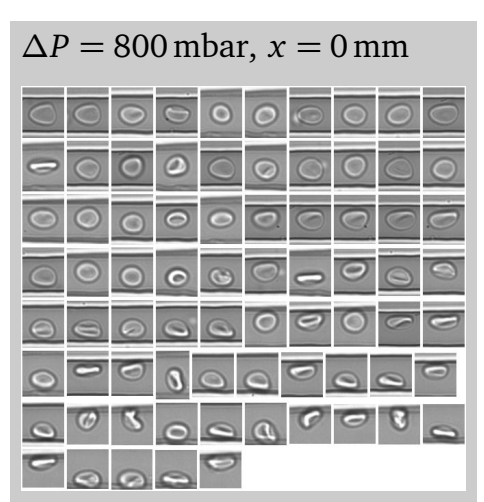

\begin{tabular}{|c|c|c|c|c|c|c|}
\hline \multicolumn{7}{|c|}{$\Delta P=900 \mathrm{mbar}, x=0 \mathrm{~mm}$} \\
\hline ब & 인 & 으으 & 00 & 0 a & (2) & 으응 \\
\hline a. & a) & a $a$ & 000 & 0 인 & OQ & 00 \\
\hline (2) & 인 & ब, & 으응 & ब. & बे & बेंब \\
\hline 의 & 알. & 응 & 응 & ㅇ. & 응 & c. 0 (c) \\
\hline 으을 & ब्र & (ㅇ) & Q. 0.0 & 으. & (ब) & 웅 \\
\hline (4) & $\overline{0}$ & 응 & (ब) & (c) & (1) & $\begin{array}{ll}\text { (4) } \\
\end{array}$ \\
\hline 응 & $\Theta$ & बब & (으응 & 0 ब & बत्ब & (2) (1) \\
\hline 0 & ㅇ․ & 00 & (c) & बन & $\Leftrightarrow \bar{\theta}$ & $\sigma 0$ \\
\hline \% 0 & 2) & बa. & (2) 0 & 잉 & 20 & 000 \\
\hline 00 & ब & ब० & $0 \sigma \theta$ & न & es & कह \\
\hline e 0 & o & $\theta 0$ & 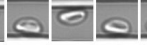 & 00 & 으 & 000 \\
\hline$\sigma_{\Omega}$ & 0 & 0 a & $00^{\circ}$ & ब0 & 0 & - \\
\hline a & & $\theta_{a}$ & ala & & & \\
\hline
\end{tabular}

\begin{tabular}{|c|c|c|c|c|c|c|c|c|c|}
\hline \multicolumn{10}{|c|}{$\Delta P=1000 \mathrm{mbar}, x=0 \mathrm{~mm}$} \\
\hline 0 & & & $\theta \theta$ & $\theta$ & e & 0 & & 이 & $\theta$ \\
\hline C & (1) $\bar{C}$ & e & e & (0) & e & $\overline{0}$ & $\theta$ & a & $\theta$ \\
\hline$\varepsilon$ & O) & $\theta$ & (2) 0 & 0 & 0 & O & 0 & 6 & \\
\hline $\mathrm{C}$ & e|c & 0 & e 0 & $\subseteq$ & 0 & $\theta$ & 3 & 이 & \\
\hline & Q $\bar{E}$ & 0 & $\overline{0}$ & $\theta$ & 0 & O & o & 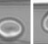 & $\theta$ \\
\hline 이 & o/c & ब & & 10 & ○) & (ब) & & & $\theta$ \\
\hline$\theta$ & $\sqrt{6}$ & ब & $\overline{\sigma \sigma}$ & $\overline{0}$ & का & का & & & 5 \\
\hline$e$ & бo & \% & $\theta$ & 0 & $\bar{\sigma}[$ & 이 & & & 0 \\
\hline$\theta$ & & & कब & e & $\theta$ & ا & ○ & & 0 \\
\hline & $0=$ & 0 & alo & 0 & إ & $\theta$ & & & 1 \\
\hline & & & & & & & & & \\
\hline
\end{tabular}

